\title{
De las excepciones en la Sustracción Internacional de persona menor de 16 años. Visión doctrinal y jurisprudencial, con énfasis en el proceso nicaragüense'
}

\author{
María José Aráuz Enríquez \\ majoarhe0I@gmail.com \\ Juez de familia, Nicaragua
}

Fecha de recibido: noviembre 2017 / Fecha de aprobación: junio 2018

La sustracción internacional de menores es una institución que se halla contenida en el Convenio de la Haya de 1980, del cual Nicaragua es país suscriptor. El contenido del Convenio estructura los mecanismos generales que sobre dicha materia cada uno de los Estados suscriptores ha de adoptar e incorporar en su ordenamiento jurídico. No obstante, la finalidad de dicho instrumento internacional consiste en la tutela del derecho de custodia y visitas propio de uno de los progenitores cuando el otro ha sustraído de su domicilio al niño, niña o adolescente. Respecto a esta materia, dentro de nuestro ordenamiento nacional, el Código de Familia sienta algunas reglas de carácter general, remitiendo en consecuencia, a lo dispuesto en los instrumentos internacionales con vigencia en nuestro Derecho, no obstante, en este trabajo se destaca la existencia de normas distintas a las que remite el Código de Familia, las cuales deben ser tenidas en cuenta para la solución de conflictos. Otro elemento en el que se centra la atención en esta investigación es la necesidad de coordinación entre las autoridades competentes, lo cual se realiza por medio del análisis de casos y de doctrina jurisprudencial de algunos países de nuestro entorno cultural; seguidamente, se describe el procedimiento tanto administrativo como judicial que pone en práctica las disposiciones del Convenio, a propósito de lo cual se evidencia que los aplicadores realizan interpretaciones inadecuadas de las normas cuando se las analiza en concurrencia con otras normas concomitantes, en especial, cuando se trata de causas con ocasión de la sustracción internacional del país de residencia habitual y de las excepciones especiales que las partes pueden oponer a la solicitud de restitución inmediata del niño, niña o adolescente. En fin, este trabajo pretende presentar una suerte de guía para una correcta implementación a los supuestos de sustracción internacional y a la vez, evidenciar la necesidad de crear una ley especial sobre la materia.

\footnotetext{
' Investigación realizada en el marco del Programa de Doctorado "Cuestiones actuales del Derecho" 2da edición de la Universidad Centroamericana (UCA), Nicaragua.
} 


\section{Abstract}

The international abduction of minors is regulated by the 1980 Hague Convention, of which Nicaragua is a subscribing country. The structure of the Convention establishes the macro regulations to be followed in order for each signatory State to adapt them to its domestic law. It also presents as a purpose the protection to the right of custody and visits that is violated with respect to one of the parents by the person who took the child from the place of habitual residence. The Family Code regulates international abduction in general and refers to international conventions.

This work demonstrates the existence of more norms that have to be taken into account both in domestic and international law in Nicaraguan legal regulation and the need to regulate this action in a special way as a result of its legal nature and the coordination that surrounds it for its correct applicability. The competent authorities, the exceptions and the national and international trends were studied, through case studies and readings of international jurisprudence. The administrative procedure before the central authority and the judicial procedure were announced, as well as the practices to be followed in order to ensure the correct application of the Abduction Convention; in the investigation has been found problems of interpretation of the norms, by the plurality of laws that converge in these cases and that of mandatory form have to be analyzed, as well as the legal regime regarding the international abduction of the country of habitual residence. This analysis should be given especially when they oppose the request for the immediate return of the child or adolescent, making use of the special exceptions that the 1980 Hague Convention establishes for this purpose. In this paper we intend to establish a guide of the applicable legal regime and the need to regulate the particularities that characterize this type of processes in order to respect the rights of children and adolescents.

\section{Key words}

International Return of Children / Legal System / interest of de child / International abduction, Exceptions

\section{Tabla de contenido}

Introducción. Antecedentes. I. Conceptos generales relativos a la sustracción internacional de niños, niñas y adolescentes. I.I. Generalidades. I.2. Sustracción internacional de menores. I.3. Residencia Habitual. 1.4. Derecho de Custodia. 1.5. Derecho de visita. 2. Estructura y excepciones del Convenio de La Haya de 1980. 2.I. De las excepciones. 2.I.I. Adaptación al nuevo ambiente. 2.I.2. No efectividad del derecho de custodia. 2.I.3. Grave riesgo de que el retorno del NNA afecte su integridad física y psicológica. 2.I.4. Oposición del niño, niña o adolescente. 2.I.5. Cuando no lo permitan los principios fundamentales del Estado Requerido. 3. El Proceso de Restitución Internacional de niños, niñas y adolescentes en Nicaragua. 3.I. Exequatur. Resultados y aportes. Lista de referencias.

\section{Introducción}

Este artículo desarrolla el régimen jurídico de la sustracción internacional de niños, niñas y adolescentes contenido en el Convenio de la Haya de 1980; dicho Convenio protege los derechos de custodia y visita, pero además establece conceptos novedosos que pocos operadores conocen en la práctica, crea excepciones cuando no procede dar lugar a la restitución internacional de una niña, niño o adolescente sustraído por uno de sus progenitores o cualquier otra persona y oponiendo cualquiera de las excepciones que contempla el Convenio. La implementación de este convenio implica la responsabilidad conjunta de las autoridades administrativas y judiciales en la 
coordinación y comunicación internacional de actividades con funcionarios de otros países. Cabe destacar que Nicaragua no tiene regulado de manera específica las particularidades de la sustracción internacional, ni las particularidades que se pueden dar en el desarrollo del juicio.

El tema desarrollado tiene relevancia en la medida que se expone la forma en que el ordenamiento nicaragüense ha avanzado en esta materia con la creación de un protocolo de actuación para los casos de sustracción internacional de menores, sin dejar de analizar las vicisitudes que la práctica plantea, especialmente cuando de aplicar el artículo 20 del C. F se trata, puesto que su contenido plantea el resguardo a la nacionalidad de los niños, niñas y adolescentes -en lo sucesivo abreviado como NNA-, cuestión que no resulta coherente con el espíritu del Convenio de la Haya de 1980, en razón de que dicho instrumento internacional, contrario sensu, prevé el retorno inmediato del NNA al lugar de residencia habitual de donde hubieren sido sustraídos, en los casos en que se hubiere violado el derecho de custodia o de visita. Se presenta además, la necesidad de colmar un vacío legal respecto a la concentración de competencias en esta materia a favor de jueces de distrito, en razón de las características específicas de este tipo de acción, tal y como se ha hecho en experiencias de reforma en México y otros países.

Es importante también señalar la tendencia en la oposición de las excepciones, para garantizar ante todo la participación y defensa del NNA y resguardar sus derechos ante este tipo de conflictos. Dentro de este contexto, no podemos soslayar que la excepción de grave riesgo establecida en el artículo 13 B del Convenio relacionado, está siendo opuesta con mayor frecuencia, argumentando violencia doméstica o intrafamiliar, en la que la persona sustractora y el NNA han vivido en el lugar de residencia habitual, además de la oposición del niño o niña, o bien del progenitor que no ejercía la custodia de forma efectiva. En la praxis la excepciones opuestas complejizan el proceso, pues plantean un punto litigioso y conlleva a las autoridades nicaragüenses a aplicar una interpretación sistemática, que conlleva a interpretar y aplicar en el caso concreto a la luz de los principios, instrumentos internacionales y derecho interno., lo que podría muchas veces estar en discrepancia con la interpretación restrictiva ampliamente consolidada por la doctrina y la jurisprudencia especialmente la de sur américa Argentina y Uruguay.

En esta materia se ha avanzado con la capacitación general a funcionarios de ambas autoridades, con la creación de un documento - protocolo de aplicación en materia de sustracción internacionalque sirve de guía, con registros tanto de expedientes administrativos como judiciales, con la conformación de una comisión interdisciplinaria compuesta por la autoridad central, poder judicial y defensoría pública, así se ha logrado observar en algunos casos una aplicación objetiva del convenio de la Haya de 1980, independientemente al hecho de que se dé lugar o no a la restitución y nos ha servido para medir el tiempo del proceso, la aplicación del Convenio así como las debilidades encontradas.

Como un aspecto a mejorar en la tramitación de estos asuntos debemos señalar que las autoridades involucradas debemos buscar cómo optimizar el tiempo que la $\mathrm{CH}$ de 1980 recomienda se ajuste a seis semanas, así mismo, se buscará como concentrar competencias y hacer uso de la comunicaciones judiciales directas de manera más fluida, tema que es fundamental considerando las características de cooperación internacional que se le ha dado al $\mathrm{CH}$ de 1980.

En tal sentido Tenorio (201I) y Dreyzin (2013), ponen de manifiesto la necesidad de las comunicaciones judiciales directas. Tenorio las divide en internas entre jueces del mismo Estado y las externas entre la autoridad judicial de enlace asignada para establecer la comunicación con los judiciales de los países solicitantes. En Nicaragua se encuentran reguladas en el artículo 56 del Protocolo de actuaciones, estableciendo la figura de la autoridad judicial de enlace y las funciones que se derivan del cargo, de igual manera hay que considerar el documento sobre los lineamientos en relación a la comunicación que para tal efecto ha trabajado La Haya. Dreyzin (2013), asegura que: “... el Juez de Enlace se está transformando en una figura forzosa en un proceso de restitución, 
ya que su conocimiento en la materia sirve para poder cumplir con los principios que deben primar en un caso de esta naturaleza". (p. 92).

Con este documento se pretende dar a conocer los conceptos generales propios en este tema de sustracción internacional de niños, niñas y adolescentes, la tendencia doctrinal y jurisprudencial sobre la naturaleza del proceso, el régimen jurídico aplicable de normas nacionales como internacionales y el comportamiento nacional e internacional aplicables en Nicaragua a las particularidades del proceso de restitución internacional.

Es importante resaltar que en Nicaragua no existe doctrina relativa a este tema, y en la praxis jurídica, existe poco conocimiento por parte de los operadores de justicia; en consecuencia, este trabajo constituye uno de los primeros artículos escritos sobre el tema con el fin de brindar una idea panorámica de la situación actual de la sustracción internacional en Nicaragua.

Esta investigación es de corte descriptivo y documental de tipo cualitativa, el método utilizado es de revisión bibliográfica, nacional e internacional, leyes, artículos de revistas científicas, análisis de sentencias nacionales e internacionales para fundamentar la tendencia en las excepciones que establece el Convenio de La Haya de 1980 y los datos estadísticos que se lleva como país, así mismo, se analizó el comportamiento que ha tenido el actuar jurisdiccional tanto en el sistema escrito como en el sistema oral con la entrada en vigencia del Código de Familia, de igual manera se analizó el tiempo de duración de los procesos con el fin de determinar la efectividad del tiempo de resolución de estos casos.

\section{Antecedentes}

La familia ha venido cambiando conforme ha evolucionado la sociedad, y en la medida que ha sido necesario, por la ampliación en la esfera económica, social y cultural, la necesidad de realización personal y familiar ha provocado la emigración de personas a países distintos del de origen. Este fenómeno, se acrecentó con políticas de apertura que existen en el comercio o tránsito de personas en diferentes países en América Latina, tal a como lo describen Durand y Schiavon (2010), "La migración intrarregional en América Latina se ha facilitado notablemente por la liberación económica del Mercosur, la comunidad Andina, tratados de libre comercio... En Centro América permite el libre tránsito entre Nicaragua, Honduras, El Salvador y Guatemala" (p.l). Y dicha circunstancia hace posible la incidencia de la sustracción internacional, respecto de lo cual Pino y Quiroz (20I5), exponen al señalar causas de conformación de familias mixtas cuando afirman: "Relaciones de personas de diversas nacionalidades, mayor facilidad de disolver el vínculo matrimonial, globalización de las relaciones laborales” (P.I3). Esta apertura en las fronteras a nivel latinoamericano y la no existencia de las mismas en la Unión Europea, ha dado como resultado que el derecho de familia trascienda las fronteras de la nacionalidad, la cultura y de los patrones comunes que teníamos como familia, derivando como características la multiculturalidad en las familias.

La transformación de la forma en que se constituye la familia por medio del fenómeno social, económico y migratorio, origina problemas familiares derivados de la filiación en cuanto a la autoridad parental o bien respecto a las responsabilidades parentales. Las relaciones que nacen entre los padres y los hijos e hijas, también se ven envueltos en los cambios de paradigmas que se dan desde la estructura patriarcal tradicional y en la especialización de los Derechos Humanos de los NNA, desde su propia perspectiva, especialmente en cuanto a la necesidad de que estos no sean considerados como tradicionalmente ha sucedido, como objeto susceptible de la tutela del padre, sino como persona y que los padres deben hacer todo lo posible para que la persona del niño y niña crezca de forma integral, pasando entonces la persona menor de edad a ser visto como otro igual, sujeto de derechos y obligaciones de acuerdo a su edad. En este sentido López (2005) afirma: "Para que el hombre pueda caminar hacia su plenitud ha de ser ayudado por los demás, lo que requerirá que estos acepten ese desarrollo y respeten el ejercicio de los medios y las facultades necesarios para ese fin."(p. I5I). 
La ideología cultural y la falta del reconocimiento de la dignidad de la persona del niño o niña dentro de la familia, genera uno de los factores que inciden en el hecho de la sustracción de la persona menor de edad del lugar de residencia habitual cuando en la familia hay conflictos. De tal manera que las causas que originan la sustracción internacional son muchas y confluyen en la materialización del traslado ilícito o bien la retención ilícita del NNA en otro país que no es el de su residencia habitual; la persona que planifica y ejecuta la sustracción, busca siempre como retornar al lugar en donde considera tendrá el apoyo legal y social, necesario para poder obtener la legalización de un hecho ilícito con el transcurrir del tiempo. Así Pino y Quiroz (2015) afirman: “... el nacionalismo judicial entendido como causa de la inadecuada solución de casos de sustracción internacional, al confiar el sustractor en un amparo legal y judicial del Estado de refugio, a la situación de hecho provocada". (p.12).

La sustracción internacional se encuentra regulada en el convenio de La Haya sobre los Aspectos Civiles de la Sustracción Internacional de Menores, del 25 de octubre del año de 1980. Nicaragua es parte de dicho Convenio por Decreto No. 54-2000, publicado en la Gaceta Diario Oficial No. II3, del 15 de junio del 2000. Aprobado por Nicaragua mediante Decreto No. 8I-2000., publicado en La Gaceta Diario Oficial No. 17I del 8 de septiembre del 2000. Proceso de adhesión y aprobación que cumple los requisitos establecidos en el artículo 138 numeral II de la Constitución Política nicaragüense. Para los efectos de este artículo se relacionará dicho instrumento como convenio de La Haya de 1980, CH de 1980.

La adopción de este instrumento internacional fue necesaria en el sentido de que todos los países miembros o Estados contratantes diesen respuesta a los problemas cada vez más evidentes e hizo posible además, la creación de la Convención Interamericana para la Restitución Internacional de Menores, a la cual, Nicaragua se adhiere mediante decreto No. 58-2002, publicado en La Gaceta Diario Oficial No. I 8 del 25 de junio del 2002, y su aprobación se dio mediante decreto Asamblea Nacional No. 3509 del 20 de Marzo del 2003. En consecuencia Nicaragua es uno de los 92 países firmantes, según refiere en video conferencia Goicoechea Ignacio. (20|4), la cantidad de países varía cada año.

\section{Conceptos generales relativos a la Sustracción Internacional de Menores}

\subsection{Generalidades}

Los Convenios Internacionales de Sustracción y de Restitución de Menores, nacen para dar respuestas a los problemas de familias mixtas o multiculturales, lo que ocasiona interpretaciones complejas de manera general, desde lo social, cultural y legal, en las acciones que se emprenden en la búsqueda del retorno inmediato del NNA que ha sido sustraído o retenido, por la pluralidad de leyes que convergen en los casos de restitución internacional. De acuerdo a la naturaleza del caso, participan de manera directa en la solicitud de restitución internacional, ambos Estados, el del lugar de residencia habitual y el Estado de acogida o refugio, que sí son suscriptores deberán seguir los lineamientos del convenio de sustracción.

Para poder aplicar de forma correcta el $\mathrm{CH}$ 1980, es necesario que la interpretación de los conceptos comunes se haga desde el espíritu del Convenio relacionado, sin menoscabar el derecho interno de cada Estado. Así lo interpreta Benavides (20I I), al expresar que "la aplicación del $\mathrm{CH}$ 1980, se aplica con el deseo de protegerles, interpretando su verdadero interés”. (p. 8I).

\section{I.3. Sustracción Internacional de Menores}

El Convenio de La Haya de 1980, no conceptualiza la terminología sustracción internacional de menores, pero indica las condiciones que conllevan a ella, de la que según las diferentes interpretaciones que dan los tribunales de justicia se derivan dos conceptos nacidos de la práctica 
que lo ubican en dos vertientes una de carácter sociológica y otra jurídica, así refiere De La Rosa (20I0).

Es interesante cómo se logra "definir" tantos elementos subjetivos que, según el autor conllevan a una sustracción internacional de menores, encasillándolo básicamente en chantaje emocional, en detrimento del otro adulto. Sin embargo, parece peligroso definir una frase en la que se involucran muchas causales que, si las etiquetamos, corremos el peligro de restringir los derechos de la persona más vulnerable en el conflicto, especialmente si en la misma no se menciona la afectación que sufre el o la menor de edad sustraído.

La otra vertiente es la de carácter jurídico, se deriva del artículo 3 del $\mathrm{CH}$ de 1980.

Se produce la sustracción internacional de menores cuando un menor es trasladado ilícitamente a un país distinto de donde reside habitualmente, violando el derecho de custodia atribuido a una persona o a una institución, o en aquellos casos en que el padre o la madre se haya trasladado con el menor para residir en otro país, e impida al otro progenitor que tenga atribuido el derecho de visita a ejercitarlo.

La sustracción internacional de menores de edad, de acuerdo con el convenio es aplicable hasta los adolescentes que hayan cumplido los 16 años, se da en la medida que se violenta el derecho de custodia que puede ser ejercido por los padres por derivación de ley $\circ$ bien que se tenga determinado el ejercicio de este derecho en una sentencia o resolución administrativa para uno de ellos, bien se puede dar el caso en que el ejercicio de este derecho fue convenido por los padres de forma notarial, de tal manera que puede ser ejercido este derecho de forma conjunta o separada.

En fin, el hecho de la sustracción consiste en que uno de los progenitores sustrae ilícitamente al niño, niña o adolescentes del lugar de residencia habitual, sin el permiso del otro padre y violenta el derecho de custodia, aunque también otra hipótesis es que el NNA haya salido del país de residencia habitual de forma lícita con el permiso del padre o la madre, y posterior al vencimiento de la vigencia de la estadía, el progenitor acompañante lo retiene ilícitamente en el país de refugio.

\subsection{Residencia Habitual}

Antes de conceptualizar la residencia habitual, para efectos de la aplicación del Convenio de La Haya de 1980, es necesario aclarar que en la doctrina, los vocablos domicilio y residencia se usan indistintamente, el lugar de residencia está dado de forma material, mientras que el domicilio es un concepto jurídico, para efectos de ubicar a una persona dentro un lugar determinado o circunscripción. La residencia según el diccionario jurídico, se ubica dentro de la clasificación del domicilio civil.

La determinación del domicilio es importante porque se requiere de un determinado lugar para ejercer sus derechos y cumplir sus obligaciones.

En materia de sustracción internacional el $\mathrm{CH}$ de 1980 no establece el término de domicilio, sino el de residencia habitual, sin embargo en la doctrina éste es parte de la clasificación de domicilios entendido éste como el domicilio legal, la determinación del mismo es importante para observar la competencia de la autoridad tanto administrativa como judicial que vaya a conocer de un caso de sustracción internacional, debiendo solicitar como Estado requirente el de residencia habitual y conocer de la solicitud de restitución como Estado requerido el país de refugio. En la aplicación latinoamericana del $\mathrm{CH}$ de 1980, han surgido conceptos jurisprudenciales por parte de la Corte Suprema de Justicia de la Nación de Argentina (CSJN), que establece que el lugar de residencia habitual es el centro de vida del menor sustraído.

El concepto anterior ha sido acogido en gran medida por la doctrina y de manera formal encontramos un concepto en el Convenio Bilateral Argentino- Uruguayo, para efectos de la 
aplicación del convenio en mención, el que establece en el artículo 3, "que a efectos del Convenio, se entiende por residencia habitual del menor, el Estado donde tiene su centro de vida el menor de edad sustraído". (Uriundo y Cruz 20II). Supone una situación de hecho que alude a estabilidad y permanencia con exclusión a toda dependencia del domicilio de menores. Debe interpretarse como el centro de vida, lugar donde vivía inmediatamente antes de la sustracción internacional. Mastrangelo (20I5).

El centro de vida se identifica en donde el NNA, ha desarrollado su personalidad y ha sido parte de ella, su cultura, su idioma, su entorno social y parental, así como el status quo que ha desarrollado.

\section{I.5. Derecho de Custodia}

El convenio de la Haya de 1980, establece en el artículo 5, los derechos que protege. Entre ellos el derecho de custodia, que para los efectos de la aplicación de este convenio, debe entenderse, como el derecho que tiene el progenitor que cuida a la persona menor de 16 años y establece el lugar de residencia habitual. Se respeta por parte, de La Haya, el derecho soberano de cada Estado de regular el derecho de custodia con sus diferentes terminologías y alcances, sin embargo, el mismo es derivado de la autoridad parental tal como se conoce en Nicaragua, conocida también como patria potestad regulada en España y últimamente responsabilidad parental como una tendencia democratizante estipulada en el Código Civil y Comercial de Argentina; de tal manera que el ejercicio de custodia comprende el cuido de la persona menor de edad de forma directa por ambos progenitores como atribución derivada de la ley o bien solamente por uno de éstos en caso de separación.

De tal manera que deberá de entenderse que la persona que ejerce el cuido directo del hijo o hija, no necesariamente implica que tiene la potestad exclusiva para decidir sobre todo lo concerniente a la dirección de la vida de éste, lo que puede implicar cambio de domicilio y residencia, sino que el progenitor no custodio debe de ser tomado en cuenta para tales decisiones.

Para efectos de garantizar el derecho de custodia el artículo 3 del mismo convenio, establece diferentes escenarios relativos al ejercicio de este derecho.

I. Que haya sido ejercido de forma conjunta, es decir que este derecho es ejercido por padre y madre derivado de la ley. No hay sentencia o resolución, porque no hay conflicto aparente. Toda la familia vive en un supuesto de armonía.

2. Que se ejerza el derecho de forma separada, es decir que solamente uno de los progenitores tiene el cuido directo del NNA y el otro por lógica tiene regulado el derecho de visita, este puede establecerse mediante sentencia, acuerdo o resolución administrativa.

El problema de la terminología y alcances relativo a la custodia varía de país a país, por ejemplo, en Argentina según refiere Mercado (20I3), "está sometido al régimen de patria potestad, que procura que ambos progenitores sean quienes decidan sobre las cuestiones de sus hijos." (p. 19); esto antes de la entrada en vigencia del Código Civil y Comercial de la Nación. CC y C, ahora se le denomina "responsabilidad parental., institución que según Cicarelli (2017), va más allá del cambio de terminología “... sino que recepta la transformación dinámica en relación a los progenitores y los hijos...” P (159); éste a su vez contiene dentro de las atribuciones derivadas de la ley el cuido personal de los hijos e hijas.

El otro supuesto que establece el $\mathrm{CH}$ de 1980, es la retención ilícita del NNA, se da cuando este ha salido legalmente de su lugar de residencia habitual con el permiso debido de ambos progenitores, pero el progenitor acompañante decide unilateralmente retenerlo en el país de visita, convirtiéndose en país de refugio por el vencimiento del plazo. 


\subsection{Derecho de Visita}

El derecho de visita, se encuentra establecido en los artículos 5 b del $\mathrm{CH}$ de 1980, establece que el "derecho de visita" comprenderá el derecho de llevar al NNA, por un período de tiempo limitado, a otro lugar diferente a aquel en que tiene su residencia habitual.

El derecho de visita, al igual que el derecho de custodia debe estar determinado por sentencia o bien podrá ser solicitado subsidiariamente una vez resuelta la solicitud de restitución internacional, aunque la provincia de Córdoba en Argentina ha regulado el derecho de visitas si en el fallo se determina no dar lugar a la restitución del NNA, decisión que comparto, para evitar mayores dilaciones en el proceso, $y$ en la misma sentencia se debería de establecer las coordinaciones necesarias y medidas a tomar para evitar que en el ejercicio de éste derecho se continúe con el circulo vicioso de la sustracción por cada progenitor.

Por su parte, el Código de Familia de Nicaragua, Ley 870, en adelante CFN, establece el régimen de comunicación, relación, trato y visitas, para ambos progenitores así como también para los familiares de estos, los que deberán ser acordados por ambos padres, no existiendo acuerdo entre ellos lo decidirá una autoridad judicial, se establece los mínimos de la relación parental al menos fin de semana de por medio y de manera equitativa la mitad del tiempo de vacaciones que se gozan durante el año tiempo que podrá pasar el menor con el progenitor no custodio, artículos 28I, 282 y 283 del CFN, sin embargo no reguló de manera específica el ejercicio del derecho de visita cuando uno de los padres resida en otro país.

En este punto se debe recordar que los derechos de familia que tienen que ver con relaciones familiares, no causan estado y pueden cambiarse o reformarse las sentencias según cambien las circunstancias. El CH de 1980, siguiendo la tendencia de garantizar el mejor interés del NNA que se encuentre en un conflicto de sustracción, establece en el artículo 21 , que la solicitud del derecho de visita, debe de realizarse siguiendo el mismo procedimiento en el caso de sustracción internacional, delegando en las autoridades centrales la colaboración necesaria para que se logre su efectividad.

\section{Estructura y excepciones del Convenio de La Haya de 1980}

\section{I. Estructura de la $\mathrm{CH}$ de 1980.}

El tantas veces mencionado Convenio se encuentra estructurado en seis capítulos: Ámbito de aplicación, autoridades centrales, restitución del menor, derecho de visita, disposiciones generales y clausulas finales. Por razón del objetivo de este artículo no serán abordarlos por capítulos sino por artículos de interés relacionado al tema.

$\mathrm{La} \mathrm{CH}$ de 1980, se caracteriza por dinamizar las coordinaciones internacionales entre autoridades administrativas y judiciales, con el fin de lograr el principio de eficacia en el tiempo debido de la protección de la custodia o contacto directo del progenitor desposeído del derecho de custodia y de garantizar el estatus quo del NNA. Por sus propias características algunos países como España, le han denominado según Reig (20I5), "como un Convenio de auxilio judicial... otros, como un convenio de reconocimiento y ejecución que se instrumentalizaba a través del exequatur". (p.242).

Parece aceptable caracterizarlo como un convenio de coordinaciones y comunicaciones internacionales, porque si no se logran solidificar las coordinaciones necesarias entre autoridades de ambas países el Convenio pierde su eficacia, en cuanto a la reducción máxima de plazos para restituir al NNA a su entorno habitual, sin embargo desde mi experiencia judicial, considero conveniente separarlo de la figura del exequátur que tiene una naturaleza y procedimiento distinto del establecido por el convenio relacionado y que únicamente es aplicable para aquellos Estados que no son firmantes de este convenio. 
La garantía de estos derechos a favor del NNA involucrado, no se logra sino se trabaja bajo el principio de cooperación coordinada entre los Estados suscriptores, así lo expresa el representante de Latinoamérica ante La Haya, que explica la necesidad de generar un clima de confianza entre los Estados involucrados en un conflicto, expresando lo siguiente: "el actuar de los Estados involucrados se reconozcan mutuamente como una única comunidad jurídica". Goicoechea (2015 y 2017). Caracterizando a la $\mathrm{CH} 1980$ como una convención que establece las herramientas iniciales de cooperación internacional entre las autoridades asignadas por cada Estado.

Es importante señalar que la $\mathrm{CH}$ de 1980, está diseñada para aplicar integralmente todos los medios modernos de comunicación rompiendo con el formalismo de los exhortos internacionales que en materia civil son completamente pertinentes, de tal manera que las comunicaciones entre autoridades tienen que ser fluidas y frecuentes en el tiempo real que se pueda, considerando los horarios de los Estados en un caso, todo con el fin de lograr que los plazos que se previeron de 6 semanas establecido en el artículo I I de la mencionada convención se logren alcanzar. Para ello los Estados deben designar a las Autoridades Centrales y a Jueces de Enlaces con los que se establece el canal abierto y seguro de comunicación.

El objetivo de reducir el plazo al máximo considerando las características, se debe a evitar que el NNA involucrado en estos casos, se apegue al nuevo entorno y pierda su identidad desarrollada en el lugar de residencia habitual, para ello las autoridades deben de identificar, desde la perspectiva paidocentrica que derechos que se le han violentado en primer lugar es al NNA involucrado y después garantizar el derecho de custodio o visitas a la persona solicitantes, logrando ese grado de sensibilidad, los autoridades podrán actuar aún de oficio y sobre la base de lo establecido en la convención. Así lo expresa Deryzin (20ll):

La protección de los derechos humanos lejos de ser un asunto limitado a la esfera de la competencia doméstica de los estados se convierte en una cuestión internacional, desde la proclamación con carácter universal de derechos, por esencia universales, dado su carácter de valor esencial en la comunidad internacional. (p.19).

Es importante para guiar a las autoridades involucradas tener en cuenta que resolver una restitución internacional, no implica entrar en el análisis de las competencias desarrolladas por cada progenitor para el ejercicio de la custodia o cuido de la persona del NNA, sino el poder garantizar a todos progenitores y NNA, que el juez competente para conocer y resolver sea el del lugar de residencia habitual; en tal sentido la $\mathrm{CH}$ de 1980 orienta evitar que la autoridad judicial que conoce de la sustracción internacional se pronuncie sobre el derecho de custodia, lo que en la práctica se hace difícil y ya lo menciona al respecto Marisa ( 2016), cuando establece que la línea divisoria entre el juicio que hace la autoridad judicial para dar lugar o no a la restitución sin entrar a valorar temas de custodia, es muy delgada.

\subsection{De las excepciones establecidas en el Convenio}

La finalidad del $\mathrm{CH}$ de 1980, es el retorno inmediato del NNA que ha sido sustraído de su lugar de residencia habitual o bien que esté siendo retenido en el lugar de acogida o refugio y se encuentre en un estatus de ilicitud, sin embargo, éste mismo instrumento internacional en aras de garantizar el equilibrio de la justicia y el mejor interés de los NNA involucrados en estos casos, previó excepciones a la restitución inmediata, y regula las mismas en el Capítulo III entre los artículos 13 y 20. Se hace necesario aclarar que lo establecido en el artículo 12 corresponde más que todo a requisitos de admisibilidad de la solicitud, y determinar como autoridad receptora si la persona solicitante ejercía de forma efectiva la custodia y el traslado violentó el derecho, y en el caso de retención ilícita, sí el progenitor consintió el traslado del NNA al país de refugio y aceptó su nuevo lugar de residencia. 
Antes de abordar las excepciones establecidas en el artículo 13 de la $\mathrm{CH}$ de 1980, se debe destacar que en la práctica judicial se ha abordado la argumentación que se hace meritoria valorar para determinar el tiempo de interposición y mejor interés del NNA, observar en primer lugar su opinión y la adaptación al nuevo ambiente, que es lo que se pretende evitar con el actuar expedito.

\section{I.I. Adaptación al nuevo ambiente}

La autoridad central o judicial que conoce de una solicitud de restitución internacional observará que la misma haya sido solicitada en el término de un año contado desde el momento en que se produjo la sustracción o retención ilícita. Si tal solicitud es presentada en tiempo, y además llena los requisitos procesales, tendrá la obligación de restituir al NNA en el tiempo de seis semanas. (Artículos II. I y II.2 del Convenio de La Haya de 1980). Este plazo solamente lo ha logrado establecer con efectividad Uruguay artículo 12 de la ley No. 18,895 publicada en diario oficial el 22 de Mayo del 2012, contando el plazo a partir de la fecha de presentación de la demanda, en este aspecto, Nicaragua solamente ha logrado cumplir el término en un caso de sustracción en donde se llegó al acuerdo de retornar al NNA a su lugar de residencia habitual, es decir el proceso no se desarrolló.

También se establece en el artículo 12 del $\mathrm{CH}$ de 1980., que habiendo transcurrido el año, la autoridad siempre podrá estimar el retorno del NNA, mientras no se demuestre que ha quedado integrado en su nuevo ambiente. Según Reig (2015), "en este caso el principal problema que se plantea en la aplicación de esta regla es el cómputo del plazo de un año." (p. 243).

Para ello, deberá oponerse la excepción del término debiéndose demostrar con pruebas periciales ese apego al nuevo ambiente, lo que puede ser muy peligroso para la efectividad de la aplicación de la $\mathrm{CH}$ de 1980, el tiempo que se tiene para interponer la acción es de un año, y una vez interpuesta la solicitud el cómputo del tiempo se detiene, independientemente del tiempo de duración en dar respuesta a la solicitud. Así lo explica González (2007), “...el momento de expiración del plazo es la presentación de la demanda solicitando su devolución, sin perjuicio de lo que tarden las autoridades administrativas y judiciales". (p. 92).

El tiempo de dilación del proceso, no es el referido en la $\mathrm{CH}$ de 1980 porque ésta carga corresponde a las instituciones y partes involucradas, sin embargo, no se puede negar que entre más tiempo transcurre en resolver una restitución, más apego se desarrolla entre el NNA y el nuevo ambiente, considerando el tiempo que duran los procesos en todas sus instancias, en las que ya se ha tenido conocimiento que en algunos casos se ha tardado más de cuatro años para la restitución. Pompo (2017), lo expresa como "una de las dificultades que presentan los procesos de restitución, el poder alcanzar el estándar de la duración". (p 257).

El conteo del plazo no se encuentra determinado por ninguna norma, lo que conlleva a que exista diversidad de interpretaciones, de tal manera que ya se ha cometido el error judicial de considerar que la falta de impulso procesal por una de las partes, trajo consigo el transcurso del plazo de un año que fue considerado por la autoridad judicial para denegar la restitución, tal y como se puede ejemplificar con el "considerando III. Sentencia Ia. Instancia del expediente 008076-ORM520 I3FM", encontramos que la motivación que hace la autoridad judicial en relación el plazo conlleva a una interpretación errada, ya que si la parte interesada presentó su solicitud de restitución internacional antes del año de la sustracción o retención ilícita, el tiempo que transcurre ante las autoridades, para dar respuesta, no debe ser nunca atribuido a la parte solicitante, siempre y cuando haya instado la causa. De igual manera esta interpretación del plazo no se debe de confundir con la falta de interés de los solicitantes que da origen a la caducidad de lo solicitado. 


\section{I.2. No efectividad del derecho de custodia}

En esta excepción existen tres circunstancias a alegar, las que pueden ser independientes, hay que recordar que el derecho de custodia es una de las atribuciones derivadas de la autoridad parental y el mismo puede ser ejercicio de forma conjunta o separada, la efectividad del ejercicio de este derecho tiene que estar derivado de la ley, mediante sentencia o resolución. En este caso, se tendrá que investigar en el país de residencia habitual si el derecho que tenía o ejercitaba la persona que sustrajo le atribuye facultades para trasladar sin el consentimiento del otro progenitor al hijo o hija en común. Según Tagle, Forcada y Seaone (2010), exponen que:

La interpretación de -ejercicio efectivo- de la custodia incluso comprende la situación de la no convivencia por justificadas razones tales como enfermedad, trabajo, estudios. Vale decir que esta situación fáctica debe de ser ponderada por el juez en cada caso particular. (p. 162).

La autoridad judicial que conoce de estos casos, tal a como lo ha expresado en innumerables conferencias Goicoechea, no puede resolver sin conocer el alcance de la norma del Estado de residencia habitual, ya que éste puede variar de acuerdo a los alcances del derecho atribuido; por ejemplo, en España en el Código Civil de Cataluña, en el artículo 236-II.6 se determina que el progenitor que ejerce la potestad parental, necesita el consentimiento expreso o tácito del otro para decidir el tipo de enseñanza de los hijos, para cambiar su domicilio si eso los aparta de su entorno habitual ...”. De ahí la importancia de las coordinaciones judiciales directas, a efectos de conocer mediante la colaboración de las autoridades del país solicitante el alcance del derecho regulado en el país de residencia habitual.

Los otros supuestos que regula el $\mathrm{CH}$ de 1980 son: consentimiento al traslado y aceptación del mismo, el consentimiento se probará con la prueba documental del permiso de salida del menor en aquellos países que lo tengan regulado, observándose la vigencia o las condicionantes del traslado, y la aceptación es que se haya producido el traslado, vencida la vigencia y con el transcurrir del tiempo se denote una aceptación a que el NNA continúe desarrollándose en el nuevo lugar de residencia. En ambos supuestos la excepción quedaría suficientemente fundamentada. Tal a como dicen Tagle, Forcada y Seaone, “... denota actitud tolerante con el desplazamiento o no retorno del menor, despoja al traslado de su condición ilícita transformándolo en un simple cambio de residencia sin consecuencias jurídicas." (p. 162).

\section{I.3 Existe grave riesgo de que el retorno del NNA afecte su integridad fisica y psicológica}

Es importante resaltar que la oposición de esta excepción es una tendencia que se viene imponiendo a nivel mundial, argumentando la parte opositora la existencia de violencia intrafamiliar que ha vivido la familia en conflicto y de forma directa la persona que sustrajo. En Nicaragua, en el $85 \%$ de los casos es la madre del NNA la sustractora y al llamado de acuerdo, se oponen al retorno del niño sustraído, por ser éste a su vez víctima indirecta de tal situación. De igual manera y desde la teoría de género, significaría una prolongación a la violencia ejercida por el hombre que trasciende las fronteras. El grave riesgo se invoca cuando el NNA es sometido a vivir en un ambiente sin armonía y donde se atenta en contra de la integridad física e intelectual de la madre del NNA o de él mismo.

Según Goicoechea (2017), se debe interpretar el grave riesgo cuando lo relacionan con la excepción 13 b de la $\mathrm{CH}$ de 1980, de forma restrictiva y con el fin de no desvirtuar el espíritu del $\mathrm{CH}$ de 1980, se debe de observar si en el país de residencia habitual existe la legislación suficiente para garantizar tanto a la madre como al NNA, la protección de sus derechos, lo que se debe de lograr mediante la confianza que se genere entre los sistemas jurídicos de cada Estado., a como diría Dreyzin (2016), en la búsqueda del diálogo entre las fuentes jurídicas de cada Estado con el fin de lograr una correcta aplicación del Derecho. Para ello la interpretación que se utilice tiene que ser restrictiva. 
La doctrina nos indica que al igual que las demás excepciones, la de grave riesgo debe de ser interpretada de forma restrictiva y que la valoración del riesgo debe referirse a la afectación directa a la NNA, que haya sido sustraído valorando que su retorno al lugar de residencia habitual afectaría la psiquis o la integridad física, más allá de la afectación derivada de la separación de sus padres, respecto a lo cual Tagle, Forcada y Seaone, (20I0), exponen que:

Puede serlo por causas que se relacionen con la idoneidad de quien solicita la restitución, ya sea que se trate de una persona que se trate con desequilibrio psíquico, adicción al alcohol, drogadicta, un abusador o por causas exógenas que se puedan catalogar de intolerables para el menor, lo que implica mirar los graves riesgos o peligros que se encontraran en el lugar de residencia habitual... (p. 162).

La afectación de la integridad física y psicológica del NNA, debe de ser valorada por el judicial de forma estricta, con ayuda de peritos en la materia, tanto del país requirente como del país de refugio; estos estudios tienen que ser desarrollados de forma inmediata o al menos tratarlos con la prioridad que amerita la urgencia de los trámites, lo que no implica que olvidar lo importante que es el resguardo de la integridad del NNA. En el proceso intelectual de valoración de pruebas que hace el judicial surge la problemática que quiere evitar el $\mathrm{CH}$ de 1980 en el artículo 16, que determina no pronunciarse sobre el fondo del conflicto es decir no pronunciarse sobre la custodia, respecto a esta práctica, Herrera (2017), expresa que nace la dificultad en el trabajo analítico de la autoridad judicial, porque se tiene que entrar a valorar las competencias desarrolladas por los progenitores en el ejercicio del cuido de la persona del niño, para determinar el riesgo alegado en pro del mejor interés de éste, implícitamente se determina con esa valoración la tendencia en la custodia, aunque en las sentencias no se haga referencia a la misma. Esta valoración desde mi punto de vista no altera el espíritu del $\mathrm{CH}$ de 1980 aludida siempre que se actúe diligentemente y el análisis judicial sea objetivo respetando los límites que te impone el Convenio.

En Nicaragua cuando se alegue violencia en los casos de restitución internacional, invocando el artículo 13 b del $\mathrm{CH}$ de 1980, la autoridad judicial debe conocer los lineamientos jurídicos de protección de los niñez y de las mujeres en contra de la violencia, por ser signatarios de la Convención sobre la Eliminación de todas las Formas de Discriminación contra la Mujer, conocidos como la CEDAW y la Convención Interamericana para Prevenir, Sancionar y erradicar la violencia contra la Mujer, conocida como Belén do Pará, de la que Nicaragua también es parte, considerando la alta tasa de incidencia de las mujeres en la sustracción internacional de NNA y la regulación especializada que la resguarda, según lo mandatan los artículos 7 y 436 del CFN. Realizar una interpretación sistemática no implica necesariamente dejar de realizar la interpretación restrictiva que es la tendencia de la Conferencia de La Haya, así como la doctrina. A este respecto, cabe señalar que, Pérez (2017), expresando en sentencia de la Suprema Corte de Justicia, No. 707, con fecha tres de agosto del dos mil doce, considera que:

“... cuando se habla de grave riesgo, debe de apreciarse que en la jerarquía de valores está el interés superior del niño, preeminente frente a otros, debiendo ponderarse si la reinstalación en la situación anterior a la retención, coloca al menor en situación de riesgo en grado de perturbación superior al impacto emocional que se deriva de la ruptura de la convivencia".

Al analizar los argumentos del artículo 13 b del $\mathrm{CH}$ de 1980, debe de considerarse si con las diferentes circunstancias que se plantean como salida al conflicto, se garantizará el interés superior del NNA, así lo sostiene la jurisprudencia argentina cuando Tagle, Forcada y Seaones (2010), han expresado lo siguiente con ocasión del análisis de sentencia del Tribunal Superior de Justicia de Córdoba, Sala Civil. A.I. No. 19, 27/12/2006 valoró que considerarse operativa la excepción invocada requiere que el NNA presente un grado de perturbación muy superior al impacto 
emocional que normalmente deriva en un niño ante la ruptura de la convivencia con uno de sus padres. (p. 165).

Según la personal experiencia judicial, la interpretación de las excepciones requiere conocer doctrina y la interpretación jurisprudencial de la excepción invocada; la autoridad judicial debe considerar las pruebas que demuestren la violencia alegada y que ésta sea actual y comprobable. Los principios de oficiosidad, igualdad objetiva y debida diligencia establecidos en el artículo 8 de la Cedaw., artículo 7 de la Belem do Pará, resultan medulares para garantizar la igualdad de trato y mediante el uso de la oficiosidad obtener las pruebas necesarias aplicando las herramientas que facilitan la coordinación internacional. En el análisis debe de utilizarse la teoría de la racionalidad y de ponderación en el desarrollo del proceso se observe la pugna de dos principios fundamentales entre el NNA y los progenitores. Así es considerado por autoridad judicial que en el considerando tres, numeral tres de la sentencia de restitución internacional del expediente No. 006437- ORM520I3 FM:

... al respecto la suscrita Judicial observa... una situación de desigualdad entre actor y demandada que deviene de las circunstancias siguientes: ... el actor ha tenido la oportunidad de conseguir cuanto documento ha considerado necesario...tanto en instancias públicas, como en fuentes privadas, presentándolos en debida forma... Por su relación directa con las instituciones. ...c. La demandada ha gestionado ante el consulado regional en Guatemala con resultados infructuosos obteniendo únicamente la recomendación de que debe acudir a los servicios de traductor autorizado que se encuentra a nivel regional solo en Costa Rica. ... Esta falta de oportunidades y recursos de la demandada constituye una forma de discriminación en su contra... fundamenta en los artículos I y 2 de la CEDAW.

El abordaje integral que implica el apoyo de otras disciplinas, debe también considerarse para recibir el apoyo de las autoridades del país de residencia habitual y solicitar la información o el estudio que sea necesario, haciendo uso de las comunicaciones judiciales directas, una herramienta que se aplica con mucha eficiencia y eficacia por las autoridades centrales, jueces de enlaces y la autoridad judicial que conoce de un caso., con el fin de lograr esa armonía de las decisiones a la luz de lo que el régimen jurídico y acuerdos con los Estados permita. Nicaragua regula esta forma de coordinación y apoyo multidisciplinar en los artículos 436, 437 y 438 del CFN.

Siendo que las características del $\mathrm{CH}$ de 1980 es de cooperación internacional, los Estados ya han aplicado ésta práctica, como Uruguay cuando en sentencia de la Suprema Corte de Justicia, No. 707, con fecha tres de agosto del dos mil doce, Pérez Manrique, Ministro redactor, expresa que: "La autoridad rogada puede apoyarse en informes de psicólogos... existiendo un riesgo serio y objetivamente constatable de que el retorno del menor secuestrado puede implicar un peligro físico o psíquico para su persona, la excepción será de aplicación".

Determinada la existencia de la violencia y el grado de esta mediante prueba pericial del país de residencia habitual y del país de refugio de ser necesario, se deberá apreciar la afectación que tiene esta circunstancia en el desarrollo de la vida del NNA, debiendo considerar que por el solo hecho de la separación ya se encuentra afectado y qué tanto elevaría ese grado de afectación el retorno de éste al ambiente violento. De igual manera, se debe de observar si es susceptible de garantizar a la parte sustractora el resguardo de medidas y atención especializada en el lugar de retorno, debiéndose de coordinar las medidas a seguir para la protección debida. La ponderación de los derechos humanos en juego en primer lugar los del NNA y de la persona sustractora así como la solicitante. El convenio del 96 de la Haya de protección a la niñez, es sumamente importante para garantizar el reconocimiento y ejecución de medidas tanto en el proceso, así como para garantizar la protección de los derechos alegados por las partes en ambos estados. 
Según ponencia de Goicoechea 20l4, se han marcado tres tendencias jurisprudenciales respecto a la interpretación del artículo 13 b de la $\mathrm{CH}$ de 1980 y entre ellas tenemos:

I.- Cuando se estima que la violencia es ejercida por la madre y no afecta al niño, según sentencia de Estados Unidos, 13-6-2013, Tribunal de Apelaciones del Segundo Circuito: Souratgar v. Fair, 720 F. 3d. 1240. Se sostuvo que "si bien se habían demostrado situaciones de violencia doméstica en contra de la madre, como ellas no habían afectado al niño no llegaban al nivel requerido para calificar en la excepción del artículo I3.b". Se ordenó la restitución a Singapur.

En este caso se ordenó la restitución conforme el espíritu del Convenio de la Haya de 1980, sin embargo, resulta interesante resaltar dos indicadores que el tribunal menciona, uno de ellos es, "que la violencia doméstica en contra de la madre, no habían afectado al niño" y el otro es "el nivel requerido", lo que deriva en preguntarnos, iquién establece ese indicador de nivel requerido?, y ¿hasta qué punto estaríamos garantizando una integralidad del desarrollo del niño en su propio interés, en donde la Madre es víctima de violencia?.

2.- Cuando es considerado que la violencia ejercida en contra de la madre también afecta al niño, así lo observamos en Sentencia: Australia, 5-I I-20 I0, Tribunal de Apelaciones, Harris V. Harris. Fam. CAFC 22I. "Se probó severa violencia contra la madre, y aunque se entendió que el niño no había sido agredido directamente, se consideró que la violencia a la madre afectaba gravemente al niño. Se determinó que no había manera de dictar medidas que protegieran a la madre de una situación de vulnerabilidad y por ende poner al niño en una situación intolerable. Se rechazó la restitución. Igual posición tomó la sentencia del Tribunal de Estados Unidos, 95-2008, Tribunal de Apelaciones del Circuito II: Baran v. Beaty, 526 F. 3d, 1340. Aunque la violencia se había ejercido contra la madre, se consideró que estos hechos y el abuso de alcohol del padre generaban riesgo para el niño. El padre tampoco había ofrecido compromisos que permitieran asegurar el regreso del niño y por ello se rechazó la solicitud de restitución a Australia.

3.- Como tercera tendencia tenemos la posición que recomienda la conferencia de La Haya, desde el espíritu de la $\mathrm{CH}$ de 1980, que expresa que, se debe de dar lugar al retorno del NNA, cuando se alegue violencia en contra de la madre o del NNA, siempre y cuando se haya demostrado es decir que sea comprobable como un primer requisito y que se tenga la certeza de que la madre y el niño serán amparados por el régimen jurídico del país de residencia habitual, en este caso, si no hay garantía de protección, no procedería el retorno del NNA. Esto equivale a desarrollar la confianza en los sistemas jurídicos de los países comprometidos con el contenido del Convenio.

Al respecto encontramos sentencia DFA- 0010-001875/2016 del Tribunal de Apelaciones de Familia de Primer Turno, de Montevideo, con fecha del 22 de Diciembre del 2016., en la que, la Ministra Bendahan, ordena el retorno de la niña a España en compañía de familiar diverso al Padre, de igual manera dicta medidas de protección y sobre la base del artículo II del Convenio de 1996, solicita la homologación de las medidas para la madre y la hija, mientras se encuentren en España y haga valer el derecho que corresponda ante el juez natural.

La respuesta multidisciplinaria se hace siempre trascendental en los casos de sustracción internacional cuando existe oposición, y la práctica de la misma no debe interpretarse como estrategias de dilación del proceso o como falta de voluntad del Estado requerido a no alcanzar los parámetros del tiempo sugeridos de las seis semanas, antes bien son necesarias para realmente garantizar con ayuda de psicóloga o trabajador social y las coordinaciones necesaria, determinar la existencia de la violencia para cumplir con los requisitos de comprobabilidad, demostrada la 
existencia de violencia se debe de garantizar si la sustractora y el NNA son sujeto de protección en el Estado de residencia habitual, tal como lo hemos abordado, sin embargo, existe también la posibilidad de la salida conciliadora tal como se puede apreciar en Sentencia No 0000I2-20I7 del Juzgado Local Único de Palacaguina Madriz, circunscripción Las Segovia, en Nicaragua, dictada el día 16 de mayo del 2017, en la que se demostró con estudios y colaboración de la autoridad central de El Salvador, la violencia ejercida por el solicitante en contra de la madre y el hijo, dando lugar a que el padre desistiera de la solicitud y admitiera los hechos, regulándose solamente el derecho de visitas a favor del niño y el padre.

También se identifican otros parámetros que garantizan el mejor interés del NNA, cuando se alega que su integridad estará en peligro; así en Uruguay encontramos también el rechazo a la solicitud de restitución internacional ante indicadores de violencia. Según presentación de Goicoechea y Castro (2014),

Uruguay, 3-8-20 I2. Corte Suprema de Justicia: Casación, IUE 9999-68-20I0 (I I85). El transcurso del tiempo, llevó a valorar el daño que le generaría al niño la restitución, además el padre, presentaba características peligrosas. Se rechazó la restitución por considerarse que el retorno no sería seguro.

En esta sentencia, habrá que observar cuáles eran esas características peligrosas que no se señalan, y que llevaron a los juzgadores a no dar lugar a la misma. Por ello creemos de vital importancia que la valoración de las pruebas, bien sean aportadas por la persona que excepciona o bien que la autoridad judicial las requiera por medio de coordinaciones y comunicaciones judiciales directas, son de suma importancia para que exista objetividad en la decisión que se tome.

También encontramos que la falta de responsabilidad en asumir las obligaciones que se derivan de la filiación, así como el aprovechamiento de las normas internacionales para buscar su propio interés, son objeto de valoraciones que deben considerar los tribunales que conocen de casos de sustracción, por ejemplo, encontramos que Argentina, rechaza la restitución de un Padre que reside en España, por la priorización que hizo de su propio interés migratorio. Partes: Defensoría Civil y Familia de $3^{\circ}$ Nominación por E. M. D. c/ P. P. F. s/ restitución del menor E. P. C. D. Tribunal: Juzgado con competencia en restitución internacional de menores, Fecha: 4-jul-20I3. Cita: MJ-JUM-79938-AR | MJJ79938 | MJJ79938. Considerando que el padre reclamante tiene residencia provisoria en España, no acredita tener vivienda propia, ni surge de autos que tenga trabajo estable, existiendo además serios indicios de que desearía la restitución del niño como una herramienta para no ser expulsado de dicho país, se rechaza el planteamiento de restitución internacional incoado.

\section{I.4. Oposición del niño, niña o adolescente al retorno inmediato}

Esta excepción garantiza de forma directa la participación del NNA, que éste pueda ser escuchado por las autoridades tanto administrativas como judiciales, evitando siempre la re victimización del NNA, cuando se aleguen hechos que atenten contra su integridad física y sicológica, ejemplos en casos de abusos sexuales o sicológicos, el fundamento legal de la participación se determina en los artículos 12 de la Convención sobre los Derechos del Niño, en adelante CIDN, artículo 17 del Código de la Niñez y adolescencia y artículo 448 del CFN. La forma adecuada de interpretación tiene íntima relación con las observaciones número 12 , I 4 y 20 del comité de los derechos del niño.

La necesidad de escuchar al NNA, radica en primer lugar en reconocerle como sujeto de derecho en los procesos que incidan en el desarrollo de su vida, además de reconocer, en la opinión que emitan, la autonomía progresiva que estos tengan de acuerdo al desarrollo de sus competencias, tal a como lo establece el artículo 5 de la CIDN. 
La materialización del derecho a ser oído, se procura que sea asistida técnicamente con ayuda de un psicólogo/a, en caso de ser necesario, con el fin de evitar preguntas inadecuadas que sometan al NNA a conflicto de lealtad en relación a sus progenitores. Entre mayor edad tenga el NNA, es más clara su expresión y la valoración deberá de considerarse de acuerdo a la edad y grado de madurez, el entorno en que ha vivido, el tiempo que ha transcurrido, la capacidad que tenga éste para expresarse respecto a la situación que lo involucra. La alusión a estos parámetros de valoración la encontramos en el informe Pérez Vera, que nos aclara el espíritu del CH de 1980, y además, resulta útil a efectos de valorar la participación de éstos, lo dispuesto en la la observación No. 20 del Comité de los Derechos del Niño, que hace la diferenciación de las competencias alcanzadas de cada niño de acuerdo a la edad del mismo considerando el entorno en donde se ha desarrollado.

Si bien es cierto que el principio del interés superior del niño, se encuentra implícito en el $\mathrm{CH}$ de 1980, en la excepción de oposición del niño, regulada en el artículo 13, lo encontramos de forma expresa, porque aún antes de la CIDN, este convenio había contemplado la necesidad de tratar al NNA como sujeto de derechos, garantizando su participación de la misma forma en que se contempla en el protocolo de actuaciones para el funcionamiento de los convenios de sustracción internacional de niños de Nicaragua, en la ley protección integral del Salvador, y los códigos de familia centroamericanos; cuestión que desde todo punto de vista resulta meritorio.

Herrera (2016), nos advierte que el grado de madurez que implícitamente nos lleva a pensar que quienes han alcanzado cierta edad de acuerdo a la ley han logrado tener la capacidad jurídica, en la praxis, no resulta precisa, pues la madurez no se logra alcanzando determinada edad, ésta es el fruto de muchos factores que convergen en el ambiente en donde se ha desarrollado el niño o niña; por ello en materia de sustracción internacional es de vital importancia escuchar a los NNA aun cuando no se alegue su oposición como excepción, porque ellos son los titulares del derecho que se pretende tutelar como es el desarrollo integral de su persona, en el lugar donde ha desarrollado social, cultural y familiarmente su vida, su identidad. Ello en aplicación necesaria del principio de interés superior y autonomía progresiva, los cuales se hallan garantizados en los artículos que van del 3 al 6 de la CIDN, y en el artículo 280 y 448 del CFN.

A este respecto se pronuncian Tagle, Forcada y Seoane (2010): "La escucha no significa resolver conforme sus deseos ya que sería depositar en el niño, niña o adolescente la decisión que compete al Tribunal". (p. I68).

Agrega además, Scotti (2013), que una de las garantías fundamentales en el proceso de restitución internacional del niño es su participación y la valoración de éstos encasillada dentro de la excepción de oposición del niño, refiere la tendencia de la jurisprudencia extranjera, mencionando la tendencia según sentencia bajadas de Incadat de la Conferencia de La Haya, de Australia, expone que "el término de la objeción debe de demostrar un sentimiento fuerte más allá de la mera expresión de una preferencia o de deseos comunes". (p. 22).

De igual manera refiere que Francia, Escocia e Inglaterra, se ha adoptado la noción de que el término "de preferencia por la vida en un país" no debe ser considerado como una objeción a la restitución. (p. 22). Igual criterio mantiene la conferencia de La Haya, la que en innumerables presentaciones ha realizado Goicoechea en su calidad de representante latinoamericano., de igual manera lo expresa Uruguay y Argentina con sus actuales legislaciones.

Sin embargo, es de vital importancia también lo que resalta Scotti (20I3) en su análisis jurisprudencial, cuando refiere que el Tribunal Suizo, ha resaltado la importancia de que los menores sean capaces de distinguir entre las cuestiones vinculadas a la custodia y las cuestiones vinculadas a la restitución" (p.23). En esto me parece loable el reconocimiento que hace Suiza, al observar la necesidad de aclarar a los NNA, el planteamiento del derecho que se pretende resguardar, para 
evitar que la manipulación del progenitor sustractor confunda las emociones y derive en una expresión del NNA viciada o alienada al respecto.

La oposición del NNA, debe de ser convincente, pertinente y adecuada a su grado de madurez, tal a como lo establece el artículo 5 de la CIDN y artículo 280 del CFN. Un niño que defienda al progenitor sustractor, es un NNA alienado o al menos manipulado. El informe explicativo que Pérez Vera, hace referencia en el punto 30 establece:

.... El Convenio admite asimismo que la opinión del menor respecto a la cuestión esencial de su retorno o no retorno pueda ser decisiva si, en opinión de las autoridades competentes, ha alcanzado una edad y una madurez suficiente. Por esta vía, el Convenio brinda a los menores la posibilidad de convertirse en intérpretes de su propio interés. Es obvio que esta disposición puede llegar a ser peligrosa si su aplicación se traduce en interrogatorios directos a jóvenes que pueden, ciertamente, tener conciencia clara de la situación pero que pueden asimismo sufrir daños psíquicos graves si piensan que se les ha obligado a elegir entre sus dos progenitores.

Es importante trasmitir que los NNA, sometidos a estos tipos de procesos, están confundidos y sometidos a conflicto de lealtad en relación a sus progenitores y eso hace que ellos no reconozcan sus derechos, porque se ven inmersos en problemas de adultos y a soluciones y respuesta tendentes a garantizar los derechos de los NNA desde la perspectiva adultista y no paidocéntrica. Por ello, la participación del NNA, puede ser en propia persona y a tal efecto deberá brindársele la defensa particular necesaria en garantía de sus derechos, las autoridades deben estudiar las formas de abordar a éste desde su propia perspectiva evitando interrogar al niño de forma directa y aclarándoles la situación en que se encuentra y que el proceso de sustracción nace y se desarrolla para garantizar sus derechos.

En tal sentido, Estrada (20II), agrupa los derechos de los NNA que se ven violentados en la sustracción internacional, y para ello los clasifica en:

Grupo I.- Principios y medidas generales: Artículo 3: Interés Superior del Niño. Artículo 6: Supervivencia y desarrollo. Artículo 12: Opinión del niño. Grupo 2.- Derechos y libertades Civiles. Artículo 8: Preservación de la identidad. Grupo 3.- Entorno familiar y otro tipo de tutela. Artículo 5: Dirección y orientaciones paternas. Artículo 9: Separación de los padres. Artículo 10: Reunificación familiar. Artículo II: Retención y traslados ilícitos. Artículo 19: Protección contra malos tratos. Artículo 20: protección de los niños privados de su medio familiar. Grupo 4.- Nivel de vida y bienestar: Artículo 27: Nivel de vida. Grupo 5.- Educación esparcimiento y actividades culturales. Artículo 28: Educación. Artículo 31: Esparcimiento, juegos y actividades culturales. Grupo 6.Medidas Especiales de Protección. (pp. 2-3).

Los derechos desglosados en la cita anterior, marcan la pauta de evaluación que deben hacer las autoridades judiciales para conceder la restitución internacional o no, los NNA durante el proceso deben de ser tratados con el respeto e igualdad debida, garantizando el derecho a la defensa. Uruguay en la ley No. 18.895, de Restitución de personas menores de dieciséis años trasladadas o retenidas ilícitamente, en el artículo 7 garantiza la defensa independiente para éstos.

En Nicaragua se creó la institución de la Procuraduría Nacional de Familia, que representa al Estado y a la niñez en estado de vulnerabilidad según lo dispone el artículo 475 del CFN; también contamos con la defensoría pública, que cubre el área de familia, sin embargo en la práctica solamente una judicial ha garantizado el derecho a la defensa de una niña en un caso de sustracción, porque se mantiene arraigado el paradigma de representación de los progenitores, sin embargo es necesario garantizar defensa independiente, por la contraposición de intereses de los padres. 
Parece pues que garantizar la participación del NNA en el proceso así como nombrarle su propio abogado, lejos de atrasar el proceso lo fortalece y lo justifica en aplicación de la doctrina integral de los derechos del niño y niña, ya que con ello se garantiza además de su participación una defensa independiente del interés que muestren sus progenitores, que muchas veces en el afán egoísta de salvaguardar sus propios derechos se olvidan de realmente lo importante.

A ello refiere Estrada (20II), cuando expresa que el contenido del artículo 27 de la CIDN, se violenta de forma drástica en una sustracción:

La calidad de vida que se le ofrece a un menor cuando se expone a una situación de sustracción, dista mucho de lo expresado en este artículo, aun cuando el menor estando con el padre sustractor pueda recibir alimentos, vestido y vivienda, las circunstancias de los niños que son sustraídos están en riesgo de serios problemas emocionales y sicológicos. (p.4).

Según la autora no solamente las condiciones sociales se afecta a los NNA, sino su salud psicológica que puede generar lesiones emocionales según el trato que se les dé en estas circunstancias, las que de por sí ya están alteradas por el proceso de separación cuando la custodia era ejercida de forma conjunta, tal como ya lo abordamos, adicionándoles los cambios bruscos del ambiente, idioma, cultura. Y peor aún el inicio de un conflicto legal incierto en el que el principal involucrado es él. Las alteraciones que sufren los NNA, según Estrada (20II) son los siguientes:

Las investigaciones demuestran cambios en los niños que son recuperados, experimentan a menudo una gama de problemas de inestabilidad e inseguridad emocional, que se manifiestan en ansiedad, problemas alimenticios, pesadillas, cambios de estado de ánimo, disturbios en el sueño, comportamiento agresivo, resentimiento, culpabilidad y angustia. Situación que viola el derecho del niño a la supervivencia y desarrollo. (p.4).

La afectación de los NNA en estos casos se hace evidente, así podemos observar la vivencia de lo experimentado por la adolescente Alondra Díaz en un vídeo, quien fue sustraída por su Padre de Estados Unidos a México. En la entrevista de restitución que se hace, ella expresa el vacío vivido por la falta de su madre durante los años que estuvo separada, así como la tristeza que le da no volver a ver a su padre. Cuestión que resulta evidencia de una afectación personal que no tiene en cuenta los detalles de la equivocación en la ejecución de la restitución. En la que se observaron violaciones a los derechos humanos de las niñas relacionadas, de tal manera que en la medida que se dé una respuesta pronta y efectiva se estará garantizando el interés superior de los NNA involucrados en la sustracción. Así lo expresa Pérez (s.f) cuando expone éste principio desde la lógica de la $\mathrm{CH}$ de 1980.

Qué es el interés superior del niño, consiste en que se respete y garantice de manera prioritaria el pleno ejercicio de sus derechos, que en el Convenio de 1980 es el derecho a no ser trasladado o retenido ilícitamente y a visitar al padre no conviviente. $Y$ a un debido acceso a la justicia, comenzando por el juez competente para determinar cuál es su interés superior en casos de conflictos interparentales. Ello determina como derecho del niño prevalente respecto de los adultos en disputa (sustractor y reclamante de restitución), la inmediata restitución para que sea el Juez de la Residencia Habitual el que decida la cuestión de fondo sobre custodia o visitas. 


\section{I.4 Cuando no lo permitan los principios fundamentales del Estado requerido}

Esta excepción resulta compleja en su interpretación por la abstracción y generalidad de la misma. Para su exégesis habría que determinar los principios fundamentales del Estado de refugio en materia de derechos humanos y observar si las garantías fundamentales que gozan en el Estado de refugio no se aseguran en el Estado de residencia habitual, la que puede darse por razones sociales, culturales y aún personales. Según el informe Pérez Vera, en el párrafo II 8 destaca su carácter excepcional que siempre debe tomar su aplicación, y en el párrafo 33 explica lo que deben considerar las autoridades en caso de denegar el retorno: I debe de comprobar no sólo la existencia de una contradicción sino también el hecho de que los principios protectores de los derechos humanos prohíben el retorno solicitado. Al respecto tenemos el fallo de la Corte Suprema de Justicia de la Nación de Argentina con fecha del 20/I2/2005, en el que no dio lugar a la restitución por encontrarse amenazado de forma permanente el progenitor sustractor de los grupos fanáticos por lo que se miraba obligado el progenitor a ocultarse, el derecho tutelado del fallo de la suprema Corte obedece al respeto del derecho a la vida.

Las otras circunstancias que pueden estimarse a dar lugar a ésta excepción es que el país de residencia habitual, esté siendo objeto de epidemias, guerras o bien potenciales desastres naturales.

\section{El proceso de restitución internacional de NNA en Nicaragua}

El libro sexto del Código de Familia regula el proceso en los artículos 425 al 561 , caracterizándolo como especial común. Este procedimiento marca en nuestro Derecho, un hito histórico, debido a la transición del sistema escrito al oral. La sustracción internacional, como acción que corresponde conocer a la jurisdicción especializada de familia-según artículos 20 y 426- nos remite a éste proceso que se compone de una parte escrita y otra oral, por lo que considero que el proceso tiene una naturaleza mixta.

La competencia de la autoridad judicial inicialmente y según lo establecía el Protocolo de actuaciones para la aplicación de los convenios internacionales relativos a la sustracción, el juez competente era la autoridad judicial de distrito de familia y donde no existiera el juez de Distrito Civil, con la entrada en vigencia del CFN, se amplía la competencia al juez de distrito de familia o local civil o local único, según lo establece los artículos 4 y 430 del CFN., en ése sentido el protocolo tuvo que ser actualizado conforme lo establece la ley, sin embargo en la práctica no es aconsejable la ampliación de competencia, por el carácter especialísimo que implica la aplicación de la $\mathrm{CH}$ de 1980, y las coordinaciones internacionales que deben hacerse para las comunicaciones judiciales o bien con la autoridad central competente; se debe tener en cuenta que no en todos los juzgados locales únicos que tienen competencia municipal se cuenta con las herramientas necesarias para actuar de forma diligente, y la amplitud de competencia dificulta la capacitación de los judiciales y personal interinstitucional involucrados en estos procesos.

La tendencia internacional para la mayor efectividad de la aplicación del $\mathrm{CH}$ de 1980 es la concentración de competencias, así lo ha establecido Uruguay, Argentina en la provincia de Córdobas, que han emitido leyes especiales para el tratamiento procesal de la acción de restitución internacional en casos de sustracción., y mediante acuerdos de Corte lo ha hecho Brasil, México y Argentina, Guatemala y República Dominicana.

La Unión Europea por su parte aprobó desde el año 2003, el Reglamento (CE), No. 2201/2003, conocido como "Bruselas II bis", regula las normativas procesales para adecuar el actuar jurídico de acuerdo al espíritu del $\mathrm{CH}$ de 1980, en ellas encontramos la determinación de la autoridad judicial competente, la obligación de tramitar en seis semanas y el reconocimiento y ejecución automática de las sentencias de los Estados miembros. 
En Nicaragua se plantea el desafío del tratamiento procesal adecuado al término de las seis semanas, así también la necesidad de concentrar competencias, la salida al planteamiento podría mediante acuerdo del Corte Suprema de Justicia, regresar la competencia a los jueces de distrito de Familia tal a como se establecía en la primera edición del protocolo de actuaciones y que con la entrada en vigencia del CFN cambió, haciéndose extensiva la delegación de competencia donde no haya juzgados de distrito de familia deberán conocer los jueces de distrito de lo Civil, la diferencia radica en que estos tienen competencia departamental y tanto la coordinación como la capacitación serían más eficaces, garantizando que las autoridades judiciales conocieran de la aplicación del $\mathrm{CH}$ de 1980 con mayor grado de profundidad en su interpretación a la luz de su objeto.

El proceso de restitución internacional se lleva en dos sedes, pues antes de iniciar el proceso en la vía judicial, la solicitud es interpuesta por medio de la Autoridad Central, que en Nicaragua corresponde al Ministerio de la Familia, adolescencia y niñez., en adelante MIFAN, instancia que debe observar que se cumplan todos los requisitos de admisibilidad. Dicho Ministerio inicia la tramitación del expediente administrativo, imprimiendo las solicitudes vía correo electrónico, se cita hasta dos veces a la persona que sustrajo con el fin de buscar un acuerdo de retorno voluntario del niño. Si no se logra el retorno voluntario, se redacta una resolución administrativa que ordena la judicialización del expediente, para ello se dan coordinaciones interinstitucionales con defensoría pública en caso de requerir representación letrada. Es importante resaltar que la resolución administrativa es requisito para la admisibilidad de la demanda, tal a como lo establece el protocolo de actuaciones en el artículo 52.I establece la obligación de acompañar a la demanda la resolución administrativa.

El espíritu del $\mathrm{CH}$ de la 1980, es actual con la diligencia debida para evitar que entre más tiempo pase mayor apego del NNA en el país de refugio, es por eso que en el artículo II del Convenio relacionado, establece que deberá de resolverse toda solicitud de restitución en un término de 6 semanas, término que ha logrado Uruguay al respecto, el problema del tiempo de duración de los procesos, se ha venido trabajando con el análisis de los comportamiento del tiempo y en Nicaragua ha mejorado significativamente, especialmente con el paso del proceso del sistema escrito al oral, acortando el mismo., en la actualidad un caso de sustracción internacional debido a su complejidad puede llevar un promedio de 3 a 6 meses. Sin embargo, el promedio anterior era de 8 meses a 1 y medio. Según estadísticas comisión interinstitucional.

La tendencia es abreviar los procesos utilizando el más expedito para alcanzar las 6 semanas, evitando la duplicidad de procesos que no tienen fuerza coercitiva, en ese contexto se hace necesario en Nicaragua revisar la efectividad del trámite que se hace en la vía administrativa, y de ser necesario eliminar el trámite y que su actuación sea para efectos de recepción, seguimiento, comunicación, coordinación y control estadístico. De tal manera que deberá de recepcionar la solicitud y sin más trámite poner en conocimiento a la autoridad judicial, para evitar un trámite administrativo que no logra el cometido que se trazó inicialmente que era la búsqueda de acuerdos según el protocolo de actuaciones. Este tipo de trámite de forma expedita lo utiliza Uruguay, Argentina y Panamá.

La demanda debe reunir los requisitos establecidos en el artículo 50 I del CFN, 52 de Protocolo y artículo 8 de la $\mathrm{CH}$ de 1980, el escrito de contestación de las pretensiones de la contraria y en el mismo escrito excepcionar tal a como lo establecen los requisitos del artículo 502 del CFN, estas excepciones deben de ceñirse a las excepciones específicas establecidas en el artículo 13 y 20 del $\mathrm{CH}$ de 1980, cuando así lo consideren conveniente, en todo caso la parte sustractora que excepciones tiene la obligación de probar tal a como lo establece el informe explicativo de la Dra. Pérez.

En el primer auto la autoridad puede ordenar las medidas que crea conveniente para evitar que el NNA sea trasladado, como retención migratoria, si el NNA no está localizable podrá hacer uso de la coordinación interinstitucional y solicitar a la Dirección de Inteligencia de la Policía Nacional para 
que le colaboren en la ubicación de éste. Además deberá poner en conocimiento a las Instituciones públicas involucradas Procuraduría de la Familia, según el artículo 475 CFN y al MIFAN según el artículo 520 del mismo código.

Terminada la fase escrita, se cita a la audiencia inicial, esta audiencia tiene establecidas sus finalidades en el artículo 524 CFN, y entre los ellos se encuentra decidir sobre las excepciones opuestas. Según experiencia personal como juez, si la persona sustractora opuso excepción no debe ser resuelta en ésta audiencia tal a como se encuentra establecido en el artículo mencionado, sino que por la naturaleza del proceso, debe aplicarse lo establecido en el artículo 530 CFN, del mismo código que establece también la facultad de resolver sobre las excepciones, me parece más idóneo hacerlo en esa audiencia ya que, al oponerse se traba la litis, y en la audiencia inicial no contará con las pruebas necesarias del país de residencia habitual o país solicitante para poder valorarlas en ese momento.

En el proceso de la acción de sustracción las excepciones especiales que nacen del artículo 13 y 20 del CFN, no deben ser resueltas en audiencia inicial sino en audiencia de vista de la causa, para lo cual se cita en audiencia inicial en el término de 15 días, siendo su finalidad que las partes traigan al proceso los hechos que motivan su pretensión a través del desarrollo de las pruebas. En esta etapa procesal ya la autoridad judicial habrá hecho las comunicaciones judiciales necesarias tanto con la autoridad judicial de enlace o bien con la autoridad central de ambos países, para poder tener conocimiento del régimen jurídico del Estado solicitante, su jurisprudencia, doctrina y de cualquier otro proceso que se esté llevando conjuntamente es el país de residencia habitual. Así lo expresa Picón (2007), cuando se refiere que "El pluralismo jurídico parte de la necesidad de una interpretación pluricultural de las leyes, es decir, del reconocimiento de diferentes funciones, contextos y fines sociales de las distintas normas jurídicas".

El sistema de valoración de la prueba es de íntima convicción, por lo que es necesaria la capacitación constante a los judiciales, la deliberación puede ser hecha de acuerdo a su experiencia y capacidad técnica al respecto.

La conciliación es un eje transversal en todo el proceso y se encuentra facultada la autoridad judicial para instarla en todo el proceso tal a como lo contemplan los artículos 450, 524 y 530 del CFN., de tal manera que con este ejercicio básicamente se desvirtúa la facultad dada a la autoridad central de buscar el acuerdo de retorno voluntario y de establecer un proceso administrativo que no cobra efectividad significativa.

Realizada la audiencia de vista de la causa, la autoridad judicial podrá deliberar y fallar en la audiencia de vistas con la pausa prudencial que necesite para hacer el juicio sobre el derecho pretendido, sin embargo, el artículo 536 CFN puede citar en el término de 5 días para audiencia de lectura de sentencia.

Es importante resaltar la importancia de la sentencia que da lugar a la restitución debe de contener las coordinación detallada de las medidas que se deban de seguir en ambos países requirente y requerido para lograr la efectividad de las medidas de ejecución y las que hayan acordado las partes durante el proceso y que se hayan logrado garantizar por las autoridades competentes en ambos Estados, el asidero jurídico interno lo encontramos en los artículos 538 y 558 del CFN, en el que se establece la obligación de detallar la forma en que se ejecutarán las medidas., sin embargo, hay que recordar que en estos procesos se trabaja con la pluralidad jurídica y habrá que tomar en consideración si las medidas establecidas en sentencia serán ejecutables en el otro país.

Para ello se hace necesario la aprobación del Convenio de La Haya de 1996, relativo a la Competencia, la ley aplicable, el reconocimiento, la ejecución y la cooperación en materia de responsabilidad parental y de medidas de protección de los niños. Este convenio brinda las herramientas necesarias para las coordinaciones entre las autoridades asignadas en cada Estado, obligando a los mismos al reconocimiento y ejecutabilidad de las medidas, no obstante, en la práctica 
se busca mediante el uso de las comunicaciones judiciales directas emitir "ordenes Espejos", que garantizan la efectividad de las medidas dictadas por la autoridad judicial que conoce la sustracción.

La aplicación simultánea de las "Ordenes Espejos", brinda mayor seguridad jurídica a las partes derivando mayor confianza en los sistemas jurídicos de cada Estado. Así se refleja en sentencia de Panamá, dictada por Juzgado Segundo de la Niñez y la Adolescencia, dictada el 5 de mayo del 2005, en la que se pormenorizó la forma en que se llevaría a cabo el ejercicio del derecho de visitas al niño en lugar de su residencia del progenitor solicitante.

En la audiencia de vistas o bien en la audiencia de lectura de sentencias, la parte que no está de acuerdo podrá hacer uso del recurso de apelación, mismo que será admitido en la misma audiencia dando el tiempo de 5 días comunes a ambas partes para presentar el escrito en donde plasmen sus intereses y ataquen a la sentencia recurrida, en ese mismo término se remitirá el expediente de primera instancia al superior respectivo en este caso al Tribunal de Apelaciones Sala Civil y de Familia por ministerio de ley, de la admisión y del término para la presentación de escrito quedan notificadas las partes en esa audiencia.

El tribunal de apelaciones una vez presentado el escrito de mejoras de intereses, citará en el término de 15 días para la única audiencia, debiendo resolver en el término de 5 días si la complejidad del caso lo amerita, si no, podrá retirarse a deliberar y dictar la sentencia debiendo leer la misma en la única audiencia. El proceso de segunda instancia se encuentra regulado en los artículos 544 al 547 del CFN.

Leída y notificada en audiencia la sentencia de segunda instancia la parte que no esté de acuerdo podrá hacer uso del recurso de Casación, de forma oral en la audiencia que correspondan, debiendo hacer la siguiente expresión: "solicito que se tenga por interpuesto el recurso de casación contra esta sentencia, el que estaré ampliando en los términos de ley" Se admite el recurso y la parte que interpuso el recurso tendrá el término de 15 días para presentar el escrito de ampliación del recurso.

Los motivos para interponer el recurso de casación se encuentran establecidos 55 I del CFN, y dispone la fundamentación en: "a) La violación notoria de derechos humanos en la actuación de las autoridades judiciales. b) Para la protección del interés superior jurídico del niño, niña o adolescente.".

La Sala de Familia o la Sala Civil por ministerio de ley de la Corte Suprema de Justicia, dispone del plazo máximo de 30 días para deliberar, votar y dictar sentencia sobre el recurso presentado y cinco días para notificar la sentencia, en casación no hay audiencias.

En Nicaragua solamente existe una sentencia que ha resuelto la Sala Civil de la Corte Suprema de Justicia en materia de sustracción internacional, que no dio lugar al recurso de Casación, confirmando la sentencia de primera y segunda instancia en la que no se da lugar a la restitución internacional, encontrándose en trámite otro recurso de Casación pendiente de resolver relativo a la acción de sustracción, por lo que se podría concluir que no tenemos jurisprudencia que estudiar al respecto.

A la lectura del trámite tal como lo establece el libro VI del CFN, en primera instancia los casos deben tardar 45 días, 25 días en segunda instancia y en Casación 50 días entre recepción y presentación de escritos, plazos para dictar la sentencia y para notificar. En total y no habiendo retraso alguno contamos con un término de 120 días hábiles para resolver en la vía judicial, lo que a todas luces no calza bien con las finalidades del $\mathrm{CH}$ de 1980, que establece en el artículo II, el plazo máximo de 6 semanas para resolver la solicitud de restitución. 
Nicaragua deberá realizar un ajuste al procedimiento, ya que el mismo no corresponde a resolver con la celeridad que el caso amerita. Si bien es cierto hemos avanzado, el protocolo de actuaciones que hoy aplicamos ha venido a brindar grandes avances en esta materia, especialmente en su primera edición que vino a estandarizar el tratamiento procesal que se le daba a la solicitud de restitución, sin embargo aunque contamos con el CFN de reciente vigencia, el procedimiento especial común que aplicamos, aún no se ajusta a las finalidades del convenio.

Se debe tomar en cuenta el interés superior del niño, inmerso en el espíritu del $\mathrm{CH}$ de 1980, que garantiza el respeto a los derechos humanos de los NNA y el derecho a su participación de manera contundente en las excepciones del artículo 13, en procura de garantizar su vida e integridad física y concediéndole su participación a través de la expresión.

Para materializar éste el principio de interés superior debe de considerarse lo expresado por Cardona (20/3), éste principio es un "Derecho subjetivo de consideración primordial, es un principio que debe ser transversal en toda la legislación y es una regla de procedimiento, que implica una serie de garantías en la evaluación y determinación del Interés Superior del Niño", y además refiere aplicar la observación No. 14 del Comité sobre los Derechos del Niño.

Con el ánimo de cumplir los compromisos que adquirimos como Estado para evitar sustracciones internacionales, se requiere regular de manera más específicas los principios tanto de interés superior del niño, así como el de autonomía progresiva, ambos necesitan de la formulación de un protocolo que guíen a las autoridades tanto administrativas como judiciales a aplicar de forma efectiva ambos principios. Tal regulación marcaría la pauta para la firma de acuerdos bilaterales entre países que aún no han aceptado la adhesión del convenio.

\section{I. Del Exequatur}

Es importante mencionar que el CFN, no deroga lo relativo al exequatur, que tenemos establecido en el Código Procesal Civil, y que no deja de ser también una vía que puede ser utilizada por los solicitantes, lo que vendría a desvirtuar la lógica del Convenio de La Haya de 1980, en relación a la concentración de autoridad central y Judicial, así como en la lógica de lo que plantea este Convenio como norma general, el retorno inmediato del menor y de forma excepcional el no retorno por causales justificadas. La existencia de la posibilidad que tienen de acudir a la vía del exequátur daría lugar a que se llevare un sub registro en cuanto a la aplicación del Convenio de La Haya de 1980. De tal manera que para evitar esta práctica incorrecta, la capacitación de la autoridad judicial en todas las instancias es necesaria, al igual que el personal auxiliar, para que al tener conocimiento de una solicitud de ejecución de sentencia extranjera por la vía de exequatur, se cumpla de forma pertinente con el ordenamiento interno y externo, dando el trámite debido.

En Nicaragua solamente tenemos un ejemplo de una solicitud de restitución de una niña con lugar de residencia habitual en Estados Unidos, solicitud que inició su primera fase mediante el trámite administrativo y al momento de judicializar el proceso, en vez de seguir lo establecido en el Convenio de La Haya de 1980 y las indicaciones generales del Protocolo de aplicación, presentó vía exequatur, la ejecución de sentencia, lo que fue admitido y orientado el cumplimiento de la sentencia en la Sala Civil, al Juez del lugar en donde se encontraba la niña. Resulta de igual manera interesante el contenido de la Sentencia que se ejecutó que en su parte conducente dice:

Corte del Circuito, Circuito Judicial Onceavo En y Para el Condado de Dade, Florida, EEUU, se dictó sentencia de orden de custodia, el día $3 \mathrm{I}$ octubre del 2012, en la caso número 2012024670-FC, división 26, Juez STANFORD BLAKE, por la cual ordena a los Sheriffs del Estado de Floridas, o cualquier otro agente del orden público, autorizado por ese estado o en cualquier Estado o país tomar de inmediato la detención de la niña de cualquier persona que la tenga en posesión y colocarla en la custodia física de su madre. 
La niña relacionada en la cita, se encontraba con el padre, la autoridad Judicial designado para ejecutar acató la orden de la Sala Civil de la Corte Suprema de Justicia, de proceder a la entrega de la niña, para ello hizo uso de las medidas que tuvo a su alcance para lograr la ejecución, la niña retornó a su país de residencia habitual.

El citado caso se contiene en el expediente se identifica en Nicaragua con el No. 00I336-ORNI20I4-FM. Sin embargo, parece importante criticar el alcance de la competencia judicial, que refleja el Juez de Estados Unidos en la sentencia relacionada cuando plasma en el contenido de la misma, que su orden deberá de cumplirse en el lugar donde se encuentre la niña, sea este Estado miembro de la Unión de Estados Americanos, así como cualquier otro país. De tal manera que me parece un abuso de competencia lo establecido en la sentencia ejecutada., ya que para tal efecto el $\mathrm{CH}$ de 1980, establece básicamente que el Juez competente para ordenar el retorno inmediato de un NNA, es la autoridad judicial del Estado requerido o país de refugio., mediante la aplicación de las normas contenidas en el convenio relacionado, lo que no fue el caso, porque se siguió bajo el procedimiento del Exequátur.

En Europa para evitar la confusión de aplicación de normas en ejecución de sentencia, es aplicable en los países de la Unión Europea, el reglamento 2201/2003 que establece en su contenido, dos figuras importantes a resaltar, la competencia de los judiciales y la eliminación del exequátur con respecto al CH de 1980, según lo expone Reig (2015).

...el Reglamento 2001/2003 introduce foros de competencias en materia de sustracción internacional de menores. Pero es que esta es quizá una de las aportaciones diferenciadoras del reglamento -sin duda, junto a la medida de eliminación del exequatur- con respecto al convenio de la Haya de 1980 donde no se establecía una normativa expresa relativa a la atribución de competencia judicial internacional... (p.256).

\section{Resultados y aportes}

La aplicación del convenio de la Haya de 1980, establece en su estructura, conceptos jurídicos para lograr la efectividad del convenio, entre ellos tenemos, custodia, residencia habitual, derecho de visita. La finalidad de éste es lograr el retorno seguro del niño, niña y adolescente al lugar de residencia habitual. El convenio no usa indistintamente la figura del domicilio y residencia como lo establece Nicaragua, sino que utiliza la figura de residencia habitual para efectos de establecer la competencia para que el Estado requirente haga la solicitud de restitución internacional al Estado de refugio.

El CH de 1980, establece en su estructura la finalidad del mismo, la competencia, el plazo sugerido para dar respuesta a las solicitudes de restitución internacional de menores de edad que hayan sido sustraídos del lugar de residencia habitual o bien que estén siendo retenidos ilícitamente, establece cuatro excepciones para que en salvaguarda del interés del niño o niña involucrados en un caso no de la restitución internacional. Es un convenio caracterizado por ser de cooperación y coordinación internacional. Sugiere un tipo de interpretación restrictiva cuando exista oposición y aleguen las excepciones establecidas en el mismo.

El protocolo de actuaciones para la aplicación de los convenios internacionales en materia de sustracción que ha desarrollado Nicaragua, representa un avance en la materia y ha venido a dar respuesta a la falta de regulación del trámite administrativo y la falta de unificación del procedimiento judicial a seguir antes de que entrara en vigencia en CF. Lo que implica en la actualidad, observar sobre la base de la finalidad del $\mathrm{CH}$ de 1980 , la efectividad del proceso administrativo que lleva a cabo la autoridad central. 
Las excepciones establecidas en los artículos 13 y 20 del CH de 1980, garantizan el interés superior del niño y el reconocimiento de la autonomía progresiva mediante la participación que hace el NNA en su oposición.

La violencia intra - familiar relacionada en los casos de sustracción internacional es alegada como una de las excepciones establecidas en el artículo I $3 \mathrm{~b}$ del convenio, la marcada practica ha generado diversidad de tendencia en las sentencias que dan salida a la violencia, la jurisprudencia Europa, Estados Unidos, Uruguay y Argentina, relacionada en el contenido del trabajo sigue dos caminos, la de observar que la violencia contra la madre es también violencia contra el NNA y los que mantienen la postura de que no. Al respecto la conferencia de la Haya orienta observar si la violencia es comprobable y si ésta es controlable en el país de residencia habitual para garantizar la integridad de la persona que sustrajo y la del NNA mediante el uso de medidas espejos, ejecutables en ambos Estados.

La escucha del niño o niña como otra de las excepciones establecidas en el $\mathrm{CH}$ de 1980, debe de ser valorada de acuerdo al grado de madurez y edad del menor, según lo señala el informe Pérez Vera. Deben de estudiarse para la objetividad de la valoración de la expresión del niño, las observaciones relativas al interés superior de aquéllos, a la participación y al reconocimiento de la autonomía progresiva de los NNA, las que encontramos en la observación número 12, 14 y 20 del Comité de los Derechos del Niño de la OEA, que nos remite a observar la edad madurativa de éste y por ende cualquier manipulación al respecto. Debe de igual manera establecerse un protocolo de actuación en la escucha de los niños que deben de seguir las autoridades para que no sean sometidos a interrogatorios directos que violenten su participación o induzcan a la respuesta.

El sistema de interpretación que debe utilizarse por la autoridad judicial ante casos de sustracción internacional, será el sistemático que no se divorcia del restrictivo que indica el $\mathrm{CH}$ de 1980 , que al contrario lo enriquece, haciendo uso de la interpretación ponderada tal a como nos enseñan las sentencias uruguayas relacionadas en este texto.

Los artículos 7 y 436 del CFN; nos orientan ese tipo de interpretación, debiendo de analizar las pruebas presentadas o traídas al proceso, con los principios generales y especiales del derecho de familia y con los instrumentos internacionales relacionados de los que Nicaragua es parte., $\mathrm{CH}$ de 1980, Cedaw, Belén do Pará y CIDN., siempre y cuando sean invocado como fundamento de la pretensión.

Nicaragua no cumple el requisito del plazo establecido en el $\mathrm{CH}$ de 1980 y el proceso especial común que regula el CFN en el libro VI, no reúne los requisitos procesales de síntesis del proceso en aras de que se dé el retorno del NNA sustraído ilegalmente o retenido ilícitamente en éste país.

El artículo 20 del CFN no regula de manera adecuada la sustracción internacional de niño, niña y adolescente ya que el elemento de nacionalidad no es indicador para valorar la sustracción internacional de menores, en vista de que la finalidad del convenio es garantizar el retorno al centro de vida del niño, independientemente de la nacionalidad de origen que éste tenga.

Para que Nicaragua de respuesta concreta a la luz del espíritu del $\mathrm{CH}$ de 1980, requiere establecer un procedimiento especial, que elimine el trámite administrativo ante la autoridad central y que éste sea la puerta de entrada y salida de las solicitudes de restitución, que concentre la competencia a los jueces de distrito de familia, como jurisdicción especializada o en donde no existan conozcan de éstos casos los jueces de distrito civil, con el fin de desarrollar capacitaciones más constantes y mejor coordinación interinstitucional., se garantice durante el proceso la defensa independiente del NNA, sometido a la sustracción., se establezca la conciliación como eje transversal en cualquier estado del proceso., que el proceso de trámite de urgencia para lograr las seis semanas establecidas en el $\mathrm{CH}$ de 1980 y que se establezcan con claridad las actuaciones de cada una de las instituciones 
involucradas; esto podría ser mediante ley especial, decreto ejecutivo o acuerdo de Corte Suprema de Justicia, tal como lo tienen establecido Uruguay, México y República Dominicana.

\section{Referencias bibliográficas}

Asamblea General. (1989). Convenio sobre los Derechos del Niño. Resolución 44/25, del 20 de noviembre de 1989.

Asamblea Nacional. (1998). Ley No. 287. Código de la Niñez y la Adolescencia. Publicado en La Gaceta Diario Oficial No. 97. Del 27 de mayo de 1998. Nicaragua.

Asamblea Nacional. (20/4). Constitución Política de la Republica de Nicaragua con sus reformas Incorporadas. Publicado en La Gaceta Diario Oficial No. 32, del 18 de Febrero de 2014. Nicaragua.

Asamblea Nacional. (20I4). Ley No. 870. Código de Familia. Publicado en La Gaceta Diario Oficial No. 190 del 8 de Octubre del 2014. Nicaragua.

Cardona J. (20I3). El interés superior del niño, principio y fin del sistema de protección infantil. Miembro del Comité de derechos del niño de la ONU. Conferencia. Recuperado de www.youtube.com

Cervera O. (20II). Capítulo IV. Los menores como titulares de la acción. En Tenorio \& Tagle. Restitución Internacional de la niñez; México: Editorial Porrúa.

CONF/ ASAM (1989). Convención Interamericana sobre Restitución Internacional de Menores. Reunión: cuarta conferencia. Del 15 de julio de 1989. Uruguay.

Conferencia de La Haya de Derecho Internacional Privado. Estadísticas del Convenio de La Haya sobre sustracción. Reunión de Jueces de La Haya y Autoridades Centrales. México. 20II. Presentación María Mayela Celis Aguilar.

Consejo de la Judicatura de México DF. (2010). Acuerdo No. 58-08/20I0. Red nacional de jueces de cooperación judicial para la protección de la niñez, en materia de restitución internacional y de Adopción. Secretaria Nacional. México DF. 24 de febrero del 2010.

Convención Americana sobre Derechos Humanos. Recuperado www.oea.com

Convención Interamericana para Prevenir, Sancionar y erradicar la violencia contra la Mujer. Recuperado www.legislacion.asamblea.gob.ni

Convención sobre la Eliminación de todas las formas de Discriminación Contra la Mujer. Recuperado www.legislacion.asamblea.gob.ni

Corte Suprema de Justicia. (2015) Protocolo de actuaciones para la aplicación de las normas internacionales en materia de sustracción y restitución internacional de niños, niñas y adolescentes en el ámbito del Derecho de Familia. Nicaragua.

Corte Suprema de Justicia. República de Guatemala. (2013). Acuerdo No. 03-2013. Determinación de la Jurisdicción, competencia y trámite para la aplicación del Convenio sobre los aspectos civiles de la sustracción internacional de menores. 23 de enero del 2013. Guatemala.

Dávila Fernández, A. (20I5). Restitución Internacional infantil, un pendiente legislativo. Tlaxcala. Recuperado de www.e-tlaxcala.mx/articulo/2015-04-07. 
De la Rosa, José. Sustracción parental de menores. Aspectos civiles, penales, procesales e internacionales. Tirant lo Blanch, 2010, p. 15.

Dreyzin de Klor, A. (2013). Restitución Internacional de Niñas y Niños. Derecho de visitas. San José C.R: Ed. Jurídica Continental.

Duran, J. \& Shiavon, J. (2010). Perspectivas Migratorias. Un análisis interdisciplinario de la migración internacional. CIDE.

Estrada, M. (20II). Derechos vulnerados en situaciones de Sustracción Internacional. Curso de Sustracción Internacional OEA. Lugar pendiente.

Flujograma de Procedimiento Administrativo. Ministerio de Familia, Adolescencia y Niñez. Dirección General de Restitución de Derechos. Haelth Ruiz. 2015.

García Cano, S. (2002). La cooperación internacional entre autoridades en el marco de la protección del menor en derecho internacional privado Español. Tesis para obtener el grado de Doctor. Universidad de Córdoba. Recuperado en http://helvia.uco.es/xmlui/bitstream/handle/I0396/405//3208299.

Goicoechea, I. (2005). Derecho de Familia. Aspectos prácticos, de la sustracción internacional de menores". Revista interdisciplinaria de Doctrina y Jurisprudencia. Número. 30. Buenos Aires. Argentina.

Goicoechea I. (2008). Derecho Procesal de Familia. Tras las premisas de su teoría general. Derecho procesal de Familia y funcionamiento de Convenios internacionales. Editorial Jurídica Continental. Costa Rica.

Goicoechea, I. (20/4), Restitución Internacional de Menores. I Congreso Centroamericano de Derecho de Familia. Colegio de Abogados y Abogadas de Costa Rica. Costa Rica. INDACAT. Hague Conference. http://www.indacat.com/index.cfm

Goicoechea, I. (20I5). Conceptos claves del convenio de 1980. Argentina. Hague Conference. http://vimeo.com

González Vicente P. (2007). La Sustracción Internacional de Menores y su Nueva Legislación. Revista Jurídica de Castilla y León. II, (pp.67-124). Recuperado https://dialnet.unirioja.es/servlet/articulo?codigo $=$ I 184774

$\mathrm{HCCH}$. (1980). Convenio sobre los Aspectos Civiles de la Sustracción Internacional de Menores; publicada el 25 de Octubre de 1980.

Jiménez Blanco, P. (2008). Litigios sobre la custodia y sustracción internacional de menores. Universidad de Oviedo. España.

La Haya. (20I2). Oficina Permanente de la conferencia de Derecho Internacional Privado de la Haya. Lineamientos emergentes, relativos al desarrollo de la red internacional de jueces de La Haya y de principios generales sobre comunicaciones judiciales, que comprende las salvaguardias comúnmente aceptadas para las comunicaciones judiciales directas en casos específicos, en el contexto de la red internacional de Jueces de La Haya. Julio 2012.

La ley modelo fue desarrollada por un grupo de expertos conformado por la Conferencia de La Haya de Derecho Internacional Privado y el Instituto Interamericano del Niño. El grupo de expertos fue coordinado por el Dr. Ricardo Pérez Manrique (Uruguay), y participaron del mismo: la Dra. María Lilian Bendahan Silveira (Uruguay), el Dr. Eduardo Cavalli Asole (Uruguay), la Dra. Raquel Gonzalez (Estados Unidos), la Dra. Graciela Tagle (Argentina), 
el Dr. Dionisio Nuñez Verdín (México), la Dra. Delia Cedenios Palacios (Panamá), y la Dra. Luz María Capuñay Chavez (Perú).

López Hurtado, C. (2010). Anotaciones sobre Derecho de Familia y su Relación con el Derecho de la Niñez y la Adolescencia. En Derecho de Familia Centroamericano: Costa Rica. Editorial Jurídica Continental.

López Jurado M. (2005). Derechos Humanos Familia y educación. Estudios sobre Educación. 8 Issn I578-700I, (Pp. I45-163). Recuperado en http://dadun.unav.edu/bitstream/10171/8882/I/Nc.pdf

Lucero, M. \& Echegary, C. (20ll). La restitución internacional de la Niñez enfoque iberoamericano doctrinario y jurisprudencial. El derecho de custodia (Articulo $5 \mathrm{CH}$ de 1980). (pp. I03-I I6). México. Ed. Porrúa.

Marín Vizueta, S. (20I5). Sustracción Internacional de menores: Interpretación del Derecho de Custodia en el Sistema Jurídico Español. En relación con el convenio de la Haya de 25 de octubre de 1980. Tesis final de Grado 20I4/I5. España.

Márquez Herrera, G (20II). Restitución Internacional de Menores. Universidad Libre de Pereira. Recuperado de http://creativecommons.org/ licenses/by-nc-nd/3.0/us/

Martrangelo, F. (2015). Jornada Nacional - Restitución Internacional de menores 22/05/20I5. Abogado especializado en Restitución Internacional de menores "Jurisprudencia de la CSJN”. Hague Conference http://vimeo.com

Mercado, D. (2013). Sustracción y Restitución Internacional de Menores. Buenos Aires: Duken, ISBN 978-987-02-6629-7 (pp. 168).

Pérez R. (s. f). Interés superior del niño en el Convenio de la Haya de 1980. Orientaciones para su interpretación.

Pérez-Vera, E, Informe Explicativo del Convenio de La Haya sobre los Aspectos Civiles de la Sustracción Internacional de Menores Recuperado de: www.hcch.net, sección: Sustracción de niños, documentos explicativos y luego en Informe Explicativo.

Pino, A \& Quiroz, E (20I5). Análisis doctrinario y jurisprudencial del convenio de La Haya sobre los aspectos civiles de la sustracción internacional de menores. Tesis para obtener el grado de Licenciado en ciencias jurídicas y sociales. Universidad de Chile, Santiago Chile.

Poder Judicial de la provincia de Córdoba. Acuerdo. (2016). No. 489. Concentración de competencias para casos de Restitución internacional de menores y régimen de visitas transfronterizos. Sitio web del poder judicial de la provincia, 9 de agosto del 2016. Argentina.

Poder Judicial de la República Oriental del Uruguay. (2012). Circular No. 175/20I2, referencia acordada No. 7758 y su reglamento acordado No. 7758. Concentración de competencias en materia de sustracción internacional. 21 de diciembre del 2012. Uruguay.

Poder Legislativo. (2012). Ley No. 18.895. Restitución de personas menores de dieciséis años trasladadas o retenidas ilícitamente. Diario Oficial No. 28473, del 22 de mayo del 2012. Uruguay.

Quani, F. (2006). Restitución internacional de menores. Ediciones Lexaustralis, Argentina.

Reig Fabado, I. (2015). El Retorno del Menor en la Sustracción Internacional de Menores. Revista Boliviana de Derecho, julio 20I5, ISSN: 2070-8I57 (No 20). Recuperado de http://www.redalyc.org/articulo.oa?id=427539916010 
Romero Y. (2007). Interpretación etnográfica y social sobre la sustracción interparental de menores. Enfoque desde la antropología jurídica. Universidad Humanística No. 64. Recuperado de http://www.redalyc.org/articulo.oa?id=79106406

Scotti, L. La protección de los Derechos Humanos en la Restitución Internacional de los niños. Revista de Derecho Privado Universidad de Ciencias Empresariales y Sociales UCES, Año II No.2, 2347-0151.

Tagle G, Forcada F \& Seoane M. (2010). La restitución internacional de Niños. Enfoque doctrinario y jurisprudencial en Argentina y España. Ed. Nuevo Enfoque Juridico. Argentina.

Tagle G. (20II). Capítulo Xl. Excepciones en el convenio de la Haya y la convención interamericana de Montevideo. En Tenorio \& Tagle. Restitución Internacional de la niñez; México: Editorial Porrúa. (pp. 219-236).

Tenorio, L. (20I I). La restitución internacional de la Niñez enfoque iberoamericano doctrinario y jurisprudencial. Las comunicaciones judiciales en la Restitución internacional de la niñez. (pp.313-348). Ed. Porrúa. México.

Tribunal Regional Federal de la 2da. Región. (2012). Resolución No T2-RSP-2012/00063. Concentración de competencia en materia de secuestro internacional de menores sobre la base del Convenio de La Haya de 1980 y de prestación de alimentos sobre la base del Convenio de 1956. 03 de agosto del 2012.Brasil.

Tribunal Regional Federal de la 4ta. Región. (2014). Resolución No. 103. Concentración de competencia en materia de secuestro internacional de menores sobre la base del Convenio de La Haya de 1980 y Convención interamericana de Restitución Internacional y solicitudes de cooperación jurídica. Diario Electrónico Administrativo $n^{\circ} 184$ Disponibilidad: 20/08/2014 Publicación: 21/08/2014. Brasil.

Uriondo, A. y Cruz, L. (20II). La restitución internacional de la Niñez enfoque iberoamericano doctrinario y jurisprudencial. Residencia habitual del niño o su centro de vida. (Pp.I39-I56), México. Ed. Porrúa.

www.diccionariojuridico.com 